\title{
A Review of Severe Thunderstorms in Australia
}

\author{
John T. Allen ${ }^{\mathrm{a}, *}$, Edwina R. Allen ${ }^{\mathrm{b}, *}$ \\ ${ }^{a}$ International Research Institute for Climate and Society, The Earth Institute of \\ Columbia University, Palisades, New York, USA. \\ ${ }^{b}$ No Affiliation, Nanuet, New York, USA.
}

\begin{abstract}
Severe thunderstorms are a common occurrence in Australia, and have been documented since the first European settlement in 1788. These events are characterized by large damaging hail in excess of $2 \mathrm{~cm}$, convective wind gusts greater than $90 \mathrm{kmh}^{-1}$ and tornadoes, and contribute a quarter of all natural hazard related losses in the country. This impact has lead to a growing body of research and insight into these events. In this article, the state of knowledge regarding their incidence, distribution, and the resulting hail, tornado, convective wind risk and lightning will be reviewed. Applying this assessment of knowledge, the implications for forecasting, the warning process and how these events may respond to climate change and variability will also be discussed. Based on this review, several potential avenues for future research and exploration are suggested, and ongoing work in the field outlined. Most notably, the need for improved observational or proxy climatologies, forecasting guidelines for tornadoes and a greater understanding of how severe thunderstorms respond to climate variability are highlighted.
\end{abstract}

Keywords: Severe Thunderstorms, Hail, Tornado, Wind, Australia

\section{Introduction}

Thunderstorms present a significant threat to life and property in Australia, and have been regularly recorded in written accounts from the period as early as five days after the arrival of the first European settlers in 1788 (Day, 2007). These storms have resulted in fatalities, destruction of homes and property, and in some cases changed the course of the settlement in terms of local population. Verbal records from the pre-European settlement of the aboriginal population suggest that such events have been the norm

*Corresponding Author: Monell Building, Lamont-Doherty Earth Observatory, 61

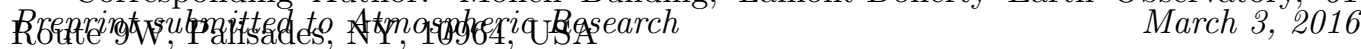

Email address: JohnTerrAllen@gmail.com (John T. Allen) 
for an extended period. Thunderstorm events have influenced nearly the entire continent and with greater frequency than any other natural hazard (Australian Bureau of Statistics, 2008). Thunderstorms can produce lightning, extreme rainfall, hailstones in excess of $2 \mathrm{~cm}$, wind gusts greater than $90 \mathrm{kmh}^{-1}$ and tornadoes. The production of any one or more of hail, damaging convective winds and tornadoes leads an event to be referred to as severe by the Bureau of Meteorology (BOM). Any of these phenomena are capable of producing high impact events on small spatial scales on the order of tens of meters to hundreds of kilometers. Examples of such events with high financial impact approaching or exceeding one billion Australian dollars (AUD) in losses include hailstorms in Sydney (Yeo et al., 1999; Harper et al., 2000), Melbourne (Buckley et al., 2010; Allen, 2012), Brisbane (Munich RE, 2015) and Perth (Buckley et al., 2010). Despite the relatively high frequency of such events, understanding their characteristics and climatology has been limited by the distribution of Australia's population, with $85 \%$ living within 50 kilometers of the coastline (Australian Bureau of Statistics, 2001). This has led to difficulties in determining the frequency of thunderstorm events over inland areas, which encompass economically crucial agricultural regions sensitive to the impacts of hail (Cremer, 1984a,b; McMaster, 1999, 2001). As of 2008, it was estimated that severe storms in Australia cost the country on average 284 million AUD per year in damage, a quarter of the total cost due to natural hazards for the continent (Middlemann et al., 2007; Crompton and McAneney, 2008). This contribution is exceeded by many single thunderstorm events that have affected metropolitan areas (e.g. the 2010 events in both Melbourne and Perth exceeded 1 billion AUD in losses; Buckley et al. (2010), while the November 2014 Brisbane hailstorm was associated with a 1.35 billion AUD insured loss; Munich RE (2015)). Since 1824, over 770 people have lost their lives to thunderstorm related phenomena in Australia, and this has the potential to greatly increase if a single high impact event over a metropolitan area occurs in the future (Blong, 2005; Middlemann et al., 2007; Crompton and McAneney, 2008).

The risks posed to the population and built environment by severe thunderstorms have spurred a body of research exploring the various impacts of these events through a range of case studies, climatology, modeling and development of forecasting procedures. Nevertheless, many aspects of severe thunderstorms in Australia are far from well understood, particularly in the context of observational and environmental climatology and climate variability. It is also important to realize that not all international advances 
in thunderstorms are necessarily representative of a continent that spans the tropics, sub-tropics and the mid-latitudes. As there has been no formal national review of the literature on severe thunderstorms in Australia to the authors' knowledge, in this paper we review the existing research that has been conducted to date, place this work into context in terms of advances from international efforts, and discuss areas which present opportunities for further research.

The structure of this review is as follows: Section 2 discusses the definition of a severe thunderstorm and the information currently available to explore severe thunderstorm characteristics and climatology. Section 3 investigates the lightning climatology for Australia and the derivative thunderstorm climatology to understand the spatial occurrence of these events and places severe thunderstorms into context. Section 4 details the existing research into severe thunderstorm climatology and phenomena such as hail, tornadoes and damaging convective winds. Extending from the climatological information, we explore the context of the forecast procedures developed for the continent in section 5. In section 6 we discuss existing research on climate variability and change relationships to thunderstorms in Australia. Finally in section 7, we discuss the limitations of the existing studies, ongoing research that will contribute to the knowledge of Australian severe weather in the future, and directions of inquiry that would ultimately benefit our understanding in the next decade.

\section{Definitions and Available Data}

\subsection{Severe Thunderstorms}

Thunderstorms are moist deep convective systems that arise from the local instability of warm moist air relative to the overlying air mass. The processes associated with releasing this instability result in the occurrence of atmospheric convection (Doswell et al., 1996). Three key factors are necessary to produce favorable environments for the development of deep convection: (i) an unstable environmental lapse rate; (ii) sufficient moisture such that there exists buoyancy; and (iii) a process to lift a parcel to the point at which it is buoyant (Doswell, 1987). For the purpose of this discussion, only deep convective storms that produce either hail, tornadoes or damaging convective winds with or without lightning are considered. Assuming that the atmosphere is unstable or is brought to a state of instability, and that deep convection initiates, a thunderstorm updraft may form when the air reaches 
the level of free convection. If sufficient moisture exists such that the atmosphere becomes saturated, cloud will form and a thunderstorm may initiate (Byers and Braham, 1949). In condensing water vapor at the lifted condensation level, the release of latent heat warms the air, further contributing to the process and generating additional buoyancy for the parcel. In deep convection, freezing can also occur, with energy released in this process driving the air within the thunderstorm high into the troposphere. Ascent continues until such time that the air is neutrally buoyant, which may be in the lower stratosphere.

Given sufficient instability and the necessary environment, deep moist convection can generate hazardous phenomena (hail, damaging convective winds, and tornadoes). Such storms may be categorized as severe thunderstorms. In Australia, the BOM classifies thunderstorms associated with any one or more of extreme rainfall causing flash flooding, hail greater than $2 \mathrm{~cm}$, wind gusts in excess of $90 \mathrm{kmh}^{-1}$ and any tornadic event as severe (Mills and Colquhoun, 1998; Harper et al., 2000). These thresholds are comparable to those used in the United States (U.S.) and Europe (Hales, 1993; Brooks et al., 2003; Doswell et al., 2005; Dotzek et al., 2009), although extreme rainfall causing flash flooding is not considered in the same category in the U.S. This exclusion can partly be explained by the existence of other nondeep convective processes that can result in extreme rainfall and subsequent flooding, including the dependence on topography and local surface conditions. Consequently there is the potential for such events to be produced by either convective or non-convective clouds that are not severe in any other sense, and which may be persistently regenerating over a location or exist in a very moist environment (Doswell et al., 1996). For the context of this discussion, we refer the reader to the numerous articles on extreme rainfall over Australia. Despite these classifications, it is important to recognize that little physical difference exists between a storm that produces near-severe, and severe thunderstorms (e.g. $1.9 \mathrm{~cm}$ vs $2.0 \mathrm{~cm}$ hail; Doswell (2001)).

Two-tier classifications of severe phenomena have also considered significant severe thunderstorms (Hales, 1993), requiring higher thresholds than those for severe phenomena and are based on report climatologies over the U.S. This second stratification is used to isolate events with an increased potential for damage to human habitation (Kelly et al., 1985; Brooks et al., 2003). Significant severe thunderstorms are defined as those producing $5 \mathrm{~cm}$ or greater hail, winds exceeding $120 \mathrm{kmh}^{-1}$ and tornadoes exceeding F2 intensity (Hales, 1993; Doswell, 2001). Such conditions have been observed rela- 
tively infrequently in Australia compared to the U.S. (Tucker, 2002; Schuster et al., 2005b; Allen et al., 2011), but do produce significant damage when the storms interact with populated areas. Nonetheless, severe hail less than $5 \mathrm{~cm}$ in Australia still causes substantial damage, particularly to agriculture (Kuhnel, 1998; McMaster, 1999; Harper et al., 2000; McMaster, 2001; Yeo, $2005)$.

It should also be noted that despite the threat lightning poses to human life (Coates et al., 1993), a storm need not produce any of the other severe phenomena in order to produce lightning, nor need produce lightning in order to produce other phenomena (Doswell, 2001). However, lightning occurrence is a useful proxy to estimate the occurrence of thunderstorms, which are requisite for each of the other severe phenomena, and thus measures of thunderdays can provide an independent spatial picture of thunderstorm occurrence (Kuleshov et al., 2002, 2006; Dowdy and Kuleshov, 2014). Thus instead of focusing explicitly on whether a study considers severe or non-severe thunderstorms, here we review literature concerning the following four phenomena associated with thunderstorms: lightning in the context of informing our understanding of severe thunderstorm occurrence, hail, damaging convective winds and tornadoes.

\subsection{Severe Thunderstorm Reports and Remotely Sensed Observations}

Reports of severe thunderstorms are sourced by in situ observations, where an observer is needed to identify a tornado, measure a fallen hailstone, or assess damaging convective winds. This can lead to a number of inconsistencies related to non-standard measurement techniques including the use of reference objects rather than analytic measurement for hail, issues with presence or lack of an observer, and perception-based intensity assessments of damage from tornadoes and damaging convective winds (Brooks et al., 2003; Trapp et al., 2006; Allen et al., 2011; Tippett et al., 2015; Allen and Tippett, 2015). In Australia, these reports are currently collated as part of the publicly available BOM Severe Thunderstorm Archive (STA; BOM, 2015), that contains data on hail, tornadoes and damaging convective winds from 1795 and is updated on an ongoing basis. Exploring these records in both Australia and in other parts of the world, observations of severe thunderstorms producing hail, damaging convective winds and tornadoes are identified to have the highest frequency of occurrence near population centers, or along road networks (Schuster et al., 2005b; Allen et al., 2011; Tippett et al., 2015; Allen and Tippett, 2015). This effect results from the sparse 
distribution of observers in less-populated rural regions, which has a significant impact on the knowledge of severe thunderstorms in these areas (Hales, 1993; Griffiths et al., 1993; Doswell, 2001). The extensive areas with a lower density population, combined with the relatively small scale across which severe thunderstorms do their damage can mean many events go unreported, and thus the understanding of the climatology for thunderstorm-related phenomena is often limited (Kelly et al., 1985; Griffiths et al., 1993; Geerts and Noke-Raico, 1995; Mills and Colquhoun, 1998). In contrast, over-reporting of events also occurs over the dense areas of population associated with cities and urban sprawl. A significant limitation encountered in Australia is that the severe weather section of the BOM was not established until 1987, and hence there was no formal collection mechanism prior to this date, leading to temporal inconsistencies which must be carefully considered (Hales, 1993; Griffiths et al., 1993). The strong tendency for existing events to be clustered towards highly populated areas is emphasized by considering a population chloropleth compared to reports (Figure 1). When combined, for example, with the noticeable increase in the number of hailstorms over this period due to changes in the monitoring network, the population clustering results in a record that has a spurious positive trend and produces questionable spatial distributions of a phenomena's occurrence. Thus it can be assessed that the STA provides a short and inconsistent observational record prior to this period, making an extensive report-based climatology challenging to produce for periods longer than a couple of decades using existing data.

For Australia there are currently two alternate potential sources of remotely sensed severe thunderstorm observations. These are derivable from the national network of rain and single-polarized Doppler radar sites (Matthews and Geerts, 1995; SREP, 2015), and from the limited satellite observations that are available over the continent (e.g. Bhaskaran et al., 2001; Cecil and Blankenship, 2012; Punge et al., 2014; Ferraro et al., 2015). The relatively short temporal records and spatial coverage available for these sources of proxy observations preclude a substantial climatological analysis. However, it is likely that these resources will prove an important contribution to the understanding of severe thunderstorms in Australia in the future, as suggested by Matthews and Geerts (1995), Geerts and Noke-Raico (1995) and Tippett et al. (2015). 


\subsection{Environmental Conditions}

The limitations of observations for severe thunderstorms and lack of remotely-sensed data to reveal information regarding the occurrence and intensity of severe thunderstorms has led to alternate approaches. The severity of a thunderstorm is governed primarily by the environmental conditions in which it develops (Brooks et al., 2003; Allen et al., 2011), however the potential for severity can be influenced by the convective mode (organization) of a thunderstorm (Thompson et al., 2012). Little physical difference exists between a storm that produces near-severe, and severe weather (Doswell, 2001), but severe storms are more commonly recognized due to their impact on the day-to-day lives of the population. The convective mode plays an important role in the generation of severe weather, with stronger and more persistent updrafts leading to a longer convective lifetime, and in sufficient steering flow, to an extension of the potential spatial impact of severe phenomena (Thompson et al., 2012). This is particularly the case for high-end severe events in the U.S., with greater than $95 \%$ of hail in excess of $5 \mathrm{~cm}$ being associated with supercell type thunderstorms (Blair et al., 2011; Thompson et al., 2012; Brooks, 2013), along with the majority of tornadic occurrences (Doswell, 2001; Thompson et al., 2012).

Extensive research has been undertaken in the U.S. and to a lesser extent Europe (Brooks et al., 2003; Brooks, 2009; Grams et al., 2011; Thompson et al., 2012) to explore the conditions favorable to severe storm development using the ingredients-based methodology adapted from Doswell et al. (1996). Primarily these investigations have revealed that the greatest controls on thunderstorm severity can be extrapolated back to the combination of vertical wind shear (VWS) over various depths of the atmosphere, and thermodynamic instability, with other important parameters specific to individual phenomena, and in some cases, the necessary ingredients are not fully understood. As a detailed assessment has yet to explore many of alternative parameters used operationally and for climatology in the U.S. in application to Australian conditions (Ryan, 1992; Hanstrum et al., 2002; Allen et al., 2011), here we focus on a common measure of atmospheric instability, Convective Available Potential Energy (CAPE), and an equally common measure of VWS, the bulk magnitude of the wind vector difference between the surface and 6 kilometers (S06). A discriminant fixed value of the product of these two parameters, and cross-validated using a set of observed Australian severe thunderstorms (Allen et al., 2011; Allen and Karoly, 2014) has been shown to perform well in identifying favorable environments for severe thunderstorm 
formation (Figure 2; though such environments will not necessarily produce a thunderstorm). As the magnitude of this product increases, through either its respective components or through joint increases, the probability of larger hail, stronger tornadoes, and more intense damaging convective winds rises. On this basis, discriminant thresholds (Figure 2) based around this product from Allen et al. (2011) are used to approximate the overall occurrence of severe thunderstorm events where few observations are available using reanalysis or model data, a situation common to most of the Australian continent (Figure 1).

\section{Lightning and Thunderstorm Climatology}

To gain a greater understanding of the climatology of severe thunderstorms for Australia, an appreciation of what is known about the spatial distribution of thunderstorms is a useful indicator of their potential climatology. A simple approach to estimate the frequency of thunderstorm occurrence is to use the concept of thunderdays, the days on which thunder was observed at an observing station. Using 300 observation stations nationally, Kuleshov et al. (2002) identified thunderdays as being most prevalent across the tropics, with secondary maxima in the interior (likely associated with the northern Monsoon across WA, NT and QLD), and in southeast Australia. Subsequent and progressive updates to this climatology using an 18-year record of automatically identified lightning flashes from a national detection network have explored both frequency of occurrence and seasonality independent of observer biases (Figure 3, Kuleshov and Jayaratne, 2004; Kuleshov, 2004; Kuleshov et al., 2006, 2009; Dowdy and Kuleshov, 2014). Most notably a bi-modal behavior was identified, with the expected spring and summer peak, along with a secondary peak over the east coast associated with intense extratropical cyclone development during the winter months. The peak occurrence through the southeast occurred during spring through early autumn, while in the tropics generally this was during the summer and into early autumn corresponding to the development of the monsoon.

Unlike STA reports, there are few spatial biases to this technique owing to the remote-sensing of lightning observations using nationwide network. However, the production of lightning does not necessarily reflect the intensity of thunderstorms or require surface based or deep convection, and as little as $400 \mathrm{Jkg}^{-1}$ of CAPE or even less can produce lightning, far below the values commonly associated with other thunderstorm-related phenomena (Doswell, 
2001; Brooks et al., 2003). Thus, while lightning data and thunderdays can be useful for obtaining a picture of thunderstorm occurrence over regions of lower population density and can be a feature of severe thunderstorms (Rasmussen and Blanchard, 1998; Kuleshov and Jayaratne, 2004; Kuleshov, 2004), they have little bearing on the distribution of other thunderstorm effects such as hail, tornadoes and damaging convective winds. In addition, low CAPE environments such as those encountered in cool-season tornado environments (Hanstrum et al., 2002) and tropical cyclone tornado environments (Edwards, 2012) rarely produce lightning, and thus lightning provides little information on the areas in which these events occur. Despite these disconnects, lightning is likely the most deadly of all phenomena associated with severe thunderstorms, accounting for approximately $85 \%$ of all fatalities in Australia associated with these events (Coates et al., 1993; Blong, 2005). Other potential impacts associated with lightning mainly relate to initiation of wildfire events, a large proportion of which result from cloud-to-ground strikes (Dowdy and Mills, 2012).

While thunderdays suggest that the greatest occurrence of thunderstorms is in the tropical regions of Darwin and the Kimberly, the Australian tropics typically do not have adequate VWS to promote strong and long-lived thunderstorms that produce the largest fraction of severe phenomena (Barnes, 2001). The short convective life-cycle, weakly organized updrafts, and an elevated freezing level result in few hail events in tropical regions. High relative humidities in the lower layers also inhibit the production of damaging convective winds. The lack of VWS to organize updrafts also reduces the possibility of supercellular tornado events. In contrast, strong cumulus updrafts and relatively weak surface flow are supportive of non-supercellular tornadoes, particularly waterspouts over near-coastal regions. The dynamic conditions being less favorable in the tropics suggests that like other locations worldwide (e.g. Brooks et al., 2003), Australian thunderstorms producing phenomena other than lightning predominantly occur in the mid-latitude regions of the continent (Barnes, 2001; Allen and Karoly, 2014).

\section{Severe Thunderstorm Phenomena: Hail, Tornadoes, Convective Wind}

\subsection{Climatology and Overview}

The majority of analyses of severe thunderstorm occurrence to date have focused on the southeast and east coast of the continent (Schuster et al., 
2005a; Yeo, 2005), with a particular bias towards NSW given the relatively widespread population and history of significant thunderstorm events (Yeo et al., 1999; Buckley et al., 2001; Leigh and Kuhnel, 2001). This does not necessarily mean that, given the required conditions, severe thunderstorms do not occur in other parts of the continent (Hanstrum and Foley, 1990; Allen, 2012; Richter et al., 2014). Instead, it suggests that the spatial distribution of frequency elsewhere is such that the probability of a population center being hit is comparatively low. In a short duration global climatology Brooks et al. (2003) and later Brooks and Dotzek (2007) estimated severe thunderstorm favorable environment frequency using a U.S. derived discriminant for reanalysis data, showing a peak frequency over eastern Australia (QLD, NSW, VIC) and across the north of the continent (NT, WA). Refining this approach and extending the climatology over the full continent independent of observations, Allen and Karoly (2014) used an environmental discriminant to develop a 32-year climatology using a different reanalysis (Figure 4). These higher resolution results identified high frequencies extending along the Great Dividing Range, across northern Australia (QLD, NT, WA) and down into southern WA. Environments in southeast QLD and northeast NSW were identified to have a greater dependence on CAPE for most of the convective warm season, while environments further south (SA, VIC, TAS, WA, southern NSW) typically depended more on S06, as would be expected given the typical southerly displaced Australian mid-latitude storm track. A limitation of this environmental approach was noted to be the excessive identification of favorable environments over the northern subtropics and tropics, which have few severe thunderstorm observations in the existing record (Figure 1). As there is little population to speak of in the northwest of Australia, the peak frequency here suggests the need for further investigation to explore severe thunderstorm occurrence in this region.

Severe thunderstorms and favorable environments for their occurrence in Australia are most frequent between midday and $7 \mathrm{pm}$ local time (Figure 5a), with the peak occurrence falling between 3 and 7 pm (Griffiths et al., 1993; Schuster et al., 2005a; Allen et al., 2011; Allen and Karoly, 2014). This is consistent with the occurrence of both non-severe and severe thunderstorms worldwide, which are generally found to peak with the diurnal cycle of surface temperature and the maximum availability of heating, and hence potential updraft strength and CAPE (Kelly et al., 1985).

Seasonally, Australian severe thunderstorms can be broken into two groups; the predominant warm season severe thunderstorms typically occurring be- 
tween September and April (Figure 5b, Harper et al., 2000; Tucker, 2002; Niall and Walsh, 2005; Schuster et al., 2005a; Allen et al., 2011; Allen and Karoly, 2014)), and cool-season thunderstorms that typically produce lowinstability tornadoes over the south of the continent in WA, SA, VIC and NSW (Griffiths et al., 1993; Hanstrum et al., 2002; Mills, 2004; Kounkou et al., 2009). As would be expected given the range of latitudes that the continent spans, there are geographic variations in the seasonal distribution between QLD and the more mid-latitude states (NSW, VIC) due to the regularity of passage of synoptic systems, with QLD tending to peak earlier (October to January and a second peak in March; Yeo, 2005) than further south, where the peak of severe thunderstorm season coincides with the spring and summer (Allen and Karoly, 2014). While many of the most severe thunderstorms are typically confined to the warmer months, there is a high degree of inter-annual variability within the occurrence both temporally and spatially.

Interannual variability has proven difficult to quantify for Australia, as much of the observed data experiences a strong increasing trend after the establishment of the severe storms sections of the BOM and growth of the storm spotters network after 1989 (Schuster et al., 2005a). Analysis using environmental proxy counts over the whole continent and the eastern half of the continent suggests considerable variability associated with the El Niño Southern Oscillation (ENSO Rasmusson and Wallace, 1983) signal (discussed in Section 6), but no apparent trend in the occurrence of favorable environments over the same period as illustrated in Figure 6.

In summary, while there is a useful appreciation for the overall aspects of the seasonal and diurnal cycle, significant limitations exist for the spatial and temporal climatology of severe thunderstorms and their associated environments, making understanding risk, variability and potential trends over the last few decades challenging.

\subsection{Hail}

Large hail is one of the most common features of Australian severe thunderstorms, occurring in 30\% of events (Griffiths et al., 1993; Harper et al., 2000). However, comparatively little is known about the distribution of larger hail diameters, as such events are uncommon in the STA (Tucker, 2002; Schuster et al., 2005a). Nonetheless, as the Sydney hailstorm and other recent events in other capital cities have illustrated, more extreme hail sizes are certainly possible in Australia (Yeo et al., 1999; Leigh and Kuhnel, 2001; 
Allen, 2012). The largest record in the existing archive suggests a maximum hail diameter of $16 \mathrm{~cm}$, though uncorroborated reports suggest historically that events have produced hail as large as $20 \mathrm{~cm}$ or larger.

Spatially, reports of severe hail in excess of $2 \mathrm{~cm}$ are most frequent toward the coastal regions and show heavy clustering characteristics toward the heavily populated urban centers (Figure 7a). However, the reports also reflect the national highways and accompanying town centers. The highest frequencies outside of the respective state capitals are found along the Great Dividing Range, stretching from western VIC, throughout eastern NSW and north to central QLD. Reports also stretch inland east of Perth, and surrounding Adelaide. Intriguingly there is a surprising number of observations over the limited road network through northwestern WA and central Australia, and in and around Darwin $\left(12.45^{\circ} \mathrm{S}\right)$ in the NT, which suggests that estimates from the environmental climatology may be less far-fetched than first thought. These are accompanied by several hail reports of $5 \mathrm{~cm}$ or greater, suggesting a propensity for organized thunderstorms such as supercells as well (Figure 7b). The majority of these larger hail reports occur over the east coast and nearer to capital cities, and are found further north reflecting the increased moisture and instability found in the subtropics. The increased bias towards the capital cities reflects the smaller swath width of the larger hail diameters, as noted for the U.S. (Blair et al., 2011).

Hailstorms have been appreciated as a relatively common occurrence for much of Australia's history (Newman, 1947; Hanstrum and Foley, 1990; Andrews and Blong, 1997; Eyre, 1992; Doswell and Brooks, 1993; Colquhoun, 1995; Crompton and McAneney, 2008). Yet it was only relatively recently that such events became a major research focus, particularly following a spate of hailstorms around the Sydney area, culminating in the record Sydney Hailstorm of 1999 (Yeo et al., 1999; Leigh and Kuhnel, 2001; Buckley et al., 2001; Schuster et al., 2005b). Characterized by extensive swathes of hail of $7.5 \mathrm{~cm}$ diameter (cricket ball), verified reports to $11 \mathrm{~cm}$ and more isolated reports as large as $13.1 \mathrm{~cm}$, the storm moved from south to north over a 5.5 hour period, tracking over eastern Sydney causing a record 1.74 billion AUD insured loss (2015 adjusted loss 4.3 billion AUD). The event occurred outside the typically perceived severe thunderstorm season, but more than ample instability and strong VWS combined to produce a highly favorable environment along the coastal plain. In recent years, similar events have impacted Brisbane, Melbourne and Perth, highlighting the need for a better understanding of climatology (Buckley et al., 2010; Allen, 2012; Munich RE, 
2015).

The Sydney storm also prompted a greater interest in hailstorm climatology over NSW and southeastern Australia in an attempt to assess the overall profile of risk (McMaster, 2001; Tucker, 2002; Schuster et al., 2005a, 2006). Notable to each of the studies was the population and spotter biases in hail observations towards the populated centers, and an increasing trend toward the end of the record associated with increased reporting (McMaster, 2001; Tucker, 2002; Schuster et al., 2005a), though verification of hail events poses challenges even on the east coast (Mills and Colquhoun, 1998). Considering rural NSW hailfall from crop insurance data and two observational records, McMaster (2001) noted a greater dependency on the frequency and intensity of hail, rather than simply absolute magnitude. This combined approach revealed that hailstorms were most frequent in the elevated areas of the Great Dividing Range in NSW and most severe in the north of the state where there is summer-dominant hailfall. This analysis is consistent with the analyzed environments (Tucker, 2002; Allen and Karoly, 2014), which have larger CAPE and more precipitable water available to form stronger updrafts in this region. Considering the east coast as a whole, Tucker (2002) noted larger mean hail sizes for the northern urban centers as compared to Melbourne, which was expected given the atmospheric differences. Somewhat surprisingly, both Sydney and Brisbane had similar mean diameters over the period 1982-2001. Controversially, Tucker (2002) also suggested that environments for hailstorms in Australia appeared to be more similar to Europe than the U.S., with lower instability but modest VWS, though based on a larger proximity climatology (Allen et al., 2011) these results seem to be unrepresentative and are perhaps related to the use of poorly timed proximity soundings from rawinsonde data. In an effort to extend the observational record, Schuster et al. (2005a) used newspaper and insurance archives together with the STA to produce a climatology from 1791 to 2003 over NSW. These results largely agreed with the work of McMaster (2001), placing large frequencies over the Great Dividing Range and its margins, and comparatively low frequencies across the lightly populated inland areas. In the Sydney region ten severe hailstorms per year were identified, though the observation evidence pointing toward a recent decrease in frequency appeared to be questionable (Figure 6), and potentially could be explained by a drought period and recent natural variability (Allen and Karoly, 2014). Schuster et al. (2005a) also analyzed maximum hailstone sizes based on 1081 storms and found similar mean maximum diameters to Tucker (2002) for Syd- 
ney $(3.8 \mathrm{~cm})$, and that $22 \%$ of all reports were over $5 \mathrm{~cm}$ in diameter, though few exceeded $10 \mathrm{~cm}$. In all three climatological studies, the peak for severe hail occurrence was found to closely match the spring and summer seasonal peak for severe thunderstorms as a whole between October and January (McMaster, 2001; Tucker, 2002; Schuster et al., 2005a). In addition to studies conducted locally, a 5-year global environment-based analysis explored hail over NSW (Hand and Cappelluti, 2011), and identified a similar spatial pattern, though this may have overestimated the frequency in comparison to Schuster et al. (2005a). These observational results are further supported by the continental frequency of severe thunderstorm favorable environments (Brooks et al., 2003; Brooks and Dotzek, 2007) for which large hail is a primary contributor to the conditions that determine the discriminant.

In attempts to decouple observations from the climatological estimates, progress toward remotely sensed climatologies has also been made in recent years using satellite microwave sensors to detect overshooting tops or hail signatures (Cecil and Blankenship, 2012; Ferraro et al., 2015). These climatologies provide a useful and independent analysis of hail risk, solidifying the picture offered by environments and observations. However both of two analyses were limited by short temporal availability (eight and one year respectively), and over-estimate hail risk in the tropics (Allen et al., 2015a; Ferraro et al., 2015). Nonetheless, these estimates are consistent with the observational and environmental records available, and reliably highlight the seasonal peak and general spatial characteristics of hail over $2.5 \mathrm{~cm}$ in diameter over the mid-latitudes.

The potential of impact of damaging hailstones is clearly related to more than just their diameter (Schuster et al., 2006), and the frequency of hailstorm occurrence, as volume of hailfall is also important, particularly for agriculture (McMaster, 2001). While impacts of hailstorms on heavily populated urban environments can produce the largest insured losses (Andrews and Blong, 1997; Crompton and McAneney, 2008) such storms can also have significant impacts on the natural environment, forestry and other horticulture processes (Cremer, 1984b,a; Myers, 1984; Houston, 1999). Alternative approaches to estimate the climatology are underway using hail occurrence derived from radar, and these will likely provide further insight over the major urban areas (e.g. Figure 8 Soderholm et al., 2016). In light of the widespread potential for hail to damage the human environment, considerable research is needed to better understand hail occurrence, the risk posed by both magnitude and volume, and how these events can potentially influ- 
ence natural and human environments by way of a better understanding of hailstorm climatology.

\subsection{Tornadoes}

Tornadoes in Australia occur in a wide range of meteorological settings (Southern, 1960; Phillips, 1965; Plukss, 1979; Minor et al., 1980; McRae et al., 2013), and can cause considerable damage to property, particularly when interacting with the major urban centers (Holcombe and Moynihan, 1978; Sills et al., 2004). A commonly held perception in Australia has been that few tornadoes are experienced, and those few that do occur are weak compared to their counterparts in the U.S. (Fujita, 1973; Minor et al., 1980; Allen, 1980; Geerts and Noke-Raico, 1995). However, while the perception of frequency appears to be a reasonable estimate (Fujita, 1973; Goliger and Milford, 1998; Allen et al., 2016), intensity assessments are not consistent with reality, as has been noted for Europe and globally (Brooks and Doswell, 2001), and is evidenced by a number of strong and damaging tornadoes in the Australian record (Holcombe and Moynihan, 1978; Plukss, 1979; Minor et al., 1980). The first documented tornado in Australia occurred in 1795 in the suburbs of Sydney, doing extreme damage to several properties over a narrow path. While numerous tornadoes were subsequently observed, the first scientific documentation of an event did not occur until the late 1800s, though events were commonly discussed in the media with varying degrees of understanding (Russell, 1889, 1891, 1893). Subsequent case studies of tornadic events were periodically undertaken, particularly between 1950 and 1980, and especially where these events impacted populated areas or drew considerable media attention (e.g. Abbe, 1906; Hunt and W.J., 1927; Phillips, 1965; Plukss, 1979; Minor et al., 1980). For a more detailed list of historical case studies we direct readers to lists that appear in Minor et al. (1980) and Allen (1980).

In comparison to the array of case studies, climatologies of tornadoes in Australia have been relatively sparse and generally temporally limited (Clarke, 1962; Evesson, 1970; Minor et al., 1980; Allen, 1980; Geerts and Noke-Raico, 1995). As with all severe thunderstorm climatologies, each of these efforts were hampered by clustering toward population centers and the coastal fringes. Particularly notable to tornadoes however were terminology changes, narrow tornado damage paths and confusion early in the record as to how an event could be defined from eyewitness reports of varying quality (Clarke, 1962; Evesson, 1970; Allen, 1980; Geerts and Noke-Raico, 1995). 
In the earliest effort, Clarke (1962) focused on 'severe local windstorms', characterized by strong winds on a lateral scale of a few miles that caused noteworthy damage to buildings and trees. This approach identified 167 tornado events from January 1950 to June 1961 using documentary records and newspapers (Figure 9a). Based on this record, Clarke (1962) assessed that the frequency of tornadoes for QLD and WA was similar to the states with the highest rate of occurrence in the U.S., but that the tornadoes were generally less intense. This initial foray prompted greater interest in case studies over the next decade, and further efforts to determine the climatology, particularly over NSW.

Evesson (1970) expanded the NSW tornado record for the period 18051966 using newspaper archival records, and a defined set of criteria that excluded events where evidence was uncertain. An intriguing result from this analysis was rather than reports of tornadoes increasing with time, there appeared to be a greater interest in tornado events in the past prompting multiple newspaper articles, whereas in the 1950s and 1960s damage to an urban center was necessary to generate a news article of public interest. To overcome issues with estimating the frequency over the state, Evesson (1970) extrapolated the frequency over the highly populated coastal fringe to suggest 15 tornadoes per year occurred over NSW. This contrasted the earlier estimate of 14.6 occuring per year for the entire country made by Clarke (1962) and later repeated by Fujita (1973). Like Clarke (1962), Evesson (1970) suggested that NSW also was comparable to the U.S. states with the highest tornado frequency. Both of these assertions were later challenged by Fujita (1973), who in post-analyzing Clarke's data suggested that the frequency of Australian tornadoes was at least order of magnitude smaller than that found in the U.S.

The growth of the record continued with Minor et al. (1980), who were surprised to find that tornadoes in Australia were perceived as more of a curiosity than a concern compared to the U.S., and were generally misunderstood by the public. Assessing a large number of case studies in addition the climatology of Evesson (1970), they identified that tornadoes in Australia exhibited many of the classic characteristics of American tornadoes, including appearance and intensity (Peterson et al., 1979; Minor et al., 1980). Their estimated rate of occurrence adjusting for population density suggested events may occur as frequently in parts of Australia as in some parts of the U.S. (Figure 9b). Taking this frequency, combined with the rare occurrence rate of strong tornadoes noted for the U.S. (approx. 1\%, Minor et al., 1980; 
Brooks and Doswell, 2001) they suggested little difference in the potential strength of tornadoes between the two continents. Further extension to the climatology followed (Allen, 1980) to build on the work of Clarke (1962) and Evesson (1970). This led to the continuation of the assumption that derived statistics were representative for the major population centers, but a gross underestimation otherwise (Figure 9c). Despite these limitations, tornadoes were arguably identified to be the source of 41 fatalities, however this climatology suggested it was rare for more than one tornado to be found in the Australian record on a given day, contrasting outbreak events commonly found in the U.S. (Fujita, 1973), though this result has since been found to be simply a function of limited data (Allen et al., 2016).

The need for an improved tornado observational record was again raised by Geerts and Noke-Raico (1995), who used the early STA archive of 700 tornadoes and performed a reanalysis of information regarding tornadoes occurring between 1960 and 1992, reflecting the most validated period of the record (Allen, 1980). Contrasting earlier studies, Geerts and Noke-Raico (1995) identified an average of 29 tornadoes per year over the continent (348 events; Figure 9d), with the frequency of tornadoes per year per $26,000 \mathrm{~km}^{2}$ over Sydney around half the frequency for central Oklahoma. The urban results also prompted discussion as to whether solely population density provided the best explanation, as other factors such as detection saturation, the spread of structures to function as a detection network and allocation of an observation to the nearest urban population appeared to contribute to the distribution. Despite these issues, Geerts and Noke-Raico (1995) suggested that outside of the coastal fringe, tornadoes were rare over the continent.

Subsequent assessments with global context used limited data from 19851995 (Goliger and Milford, 1998), and noted that the estimates by Minor et al. (1980) were overstated, and the frequency of tornado occurrence closer to Fujita (1973)'s assessment. Despite indicating lower frequency than Geerts and Noke-Raico (1995), these results were suggested to be complementary, owing to the localized regional scales considered in the Australia only study. Assessing global tornado frequency using an environment proxy for a short period, Brooks et al. (2003); Brooks and Dotzek (2007) and later updated by Tippett et al. (2015) identified modest frequencies of environments favorable to the development of tornadoes over eastern Australia, but non-zero probabilities over much of the continent. This result was consistent with estimates derived from observations, suggesting that like most of the world, the frequency of tornadoes is considerably rarer than for the U.S. This suggestion 
was further supported by Allen et al. (2016), exploring the media-alleged 'record' 2013 tornado season of 63 events in the context of the digitized STA. This identified that the significant under-reporting of tornadoes continues into the present, despite a spatial distribution similar to those of earlier studies.

The seasonal cycle of tornado frequency was also revealing in addition to the climatology of frequency (Griffiths et al., 1993; Geerts and Noke-Raico, 1995). This suggested a bi-modal seasonal cycle that was unlike the pattern in the U.S. with an early spring/summer peak and a secondary peak in the early winter months. The variations over the length of the record also appeared to suggest a weakening seasonal cycle, with contributions from either large interannual or decadal variability or the increasing detection of tornadoes occurring in alternate environmental conditions over the continent (Geerts and Noke-Raico, 1995). Subsequently, tornadoes such as the event described by Southern (1960) were identified as cool-season events, characterized by low but surface based instability environments (200-400 $\mathrm{Jkg}^{-1}$ CAPE) accompanied by high low-layer VWS (Geerts and Noke-Raico, 1995; Hanstrum et al., 2002; Mills, 2004; Kounkou et al., 2009). These cool-season tornadoes were identified to comprise a large fraction of the overall climatology, and were commonly found over southwestern WA, southern SA and western VIC. Based on environment derived proxies, Hanstrum et al. (2002) suggested that approximately 8 days per year were associated with conditions favorable to cool-season tornado development over both regions, highlighting a substantial risk. Another contribution in relatively low instability also was identified to originate from tropical cyclone tornadoes (Edwards, 2012), which have been identified in isolated cases such as Tropical Cyclone Joan (Minor et al., 1980; Geerts and Noke-Raico, 1995) and more recently in Extropical Cyclone Oswald (H. Ramsay, pers. comm.). Perhaps uniquely to Australia, a wildfire in 2003 also induced a strong tornado beneath the base of a pyro-cumulonimbus, causing significant damage and rapid spread of the fire (Fromm et al., 2006; Cunningham and Reeder, 2009; McRae et al., 2013).

The analysis of tornadoes in 2013 (Allen et al., 2016) further illustrated the wide range of formative environments of tornadoes in Australia that included many of the environments commonly encountered worldwide. This suggests a higher risk of tornadoes for Australia than applying a single criteria from the U.S. may reveal (e.g. Brooks et al., 2003).

Common to each of these climatological studies has been insufficient observations to assess the overall risk of tornadoes to the continent. Yet despite 
this limitation, the risk assessed from these observational studies has influenced engineering assessments over parts of the continent (e.g. Melaragno, 1976). This, combined with the apparent risk to heavily populated urban areas (Geerts and Noke-Raico, 1995; Allen et al., 2016), suggests a need to better understand the intensity and occurrence of tornadoes for the continent as such events are rarely assessed in the field. Further efforts are necessary to update the climatology to document and improve the existing STA record of 1273 tornadoes (Figure 9e), and to expand this record using historical archives similar to the efforts of (Grazulis, 1993) for the U.S. Preliminary work towards this goal has doubled the number of confirmable tornado observations over the period 1795-1910, greatly improving the spatial distribution (Figure 9f), while providing further metadata to the existing STA archive. There also appears to be a significant need to explore applications of environmental proxies similar to Brooks et al. (2003) to assess the climatological risk for at least the last three decades, and develop proximity climatologies of tornado favorable environments to assess alternate formative environments and develop local forecasting guidelines.

\subsection{Damaging Convective Winds}

Damaging convective winds produced by thunderstorms can pose a widespread hazard, leading to wind gusts up to and over $200 \mathrm{kmh}^{-1}$ that can destroy homes, snap trees and impact areas of a greater spatial extent than tornadoes (Geerts, 2001; Richter et al., 2014). Combined hazards can also arise when such winds occur in tandem with large damaging hail in supercell thunderstorms, propelling them horizontally against structures, a situation commonly experienced in southeast QLD and along the east coast (Eyre, 1992; Doswell and Brooks, 1993; Colquhoun, 1995; Richter et al., 2014; Munich RE, 2015). Often damaging convective wind events can be challenging to differentiate from weak tornadoes, leading to a tendency for the two to be considered jointly in some cases (Clarke, 1962; Evesson, 1970). The vast range of environments that promote the formation of wet, hybrid and dry microbursts that typically produce damaging convective wind events (Wakimoto, 2001) also make it difficult to proxy their occurrence using environments, as do limitations of the observed record (Geerts, 2001). The most challenging element of the observed record is isolating the winds associated with thunderstorm gusts, rather than synoptic scale events, and this issue is particularly pronounced for anemometer data (Wang et al., 2013), and to a lesser extent in the STA. This distinction is important, as damaging convective winds 
and non-convective (synoptic) wind gusts have different probability curves, suggesting that they need to be considered independently (Holmes, 2002). Further to this issue, without anemometer data, damaging convective winds are notoriously poorly estimated, leading to issues with classification and exaggeration (Trapp et al., 2006). Thus predominantly, studies for damaging convective winds over Australia have focused on anemometer records, and performed manual exclusion of non-convective events (Geerts, 2001). Geerts (2001) developed a climatology for NSW from 9 anemometers, and illustrated that damaging convective wind gusts were more prevalent on or west of the Great Dividing Range during November to December, though not in the western plains where lightning climatology also reveals thunderstorms to be infrequent. Dry microbursts were found to be the most common source of damaging convective winds in this record, while the distribution of wind gust magnitudes was exponentially decreasing with increasing intensity. These results highlighting dry microbursts are not reflective over southeast QLD or east of the Great Dividing Range, where hybrid microbursts are more common, particularly with high precipitation supercells (Eyre, 1992; Colquhoun, 1995; Richter et al., 2014).

An alternate application for anemometer data is to consider the distribution of damaging convective wind occurrences statistically using extreme value theory. Holmes (2002) used a peaks-over-threshold extreme value approach from recorded anenometer measurements to designate the 500-year wind standards return level for Australia, identifying that for each of the state capitals, damaging convective winds were the most important factor, excluding Perth where synoptic winds were generally stronger, and necessitated the building standard requirement of resistance to $162 \mathrm{kmh}^{-1}$ gusts. More recently, approaches using reanalysis environment data downscaled to $14 \mathrm{~km}$ resolution have been explored to spatially extend this approach over Tasmania and approximate the 500-year return levels for wind magnitude from thunderstorms from extreme value theory (Sanabria and Cechet, 2010; Cechet et al., 2012). These results suggest that the overall hazard from these events was less than from synoptic winds, but still returned values of $133.2 \mathrm{kmh}^{-1}$ for the north, and $122.4 \mathrm{kmh}^{-1}$ for the south. These methods provide a way to assess risk for damaging convective winds, though do not provide information regarding its occurrence, and are subject to limitations arising from the problems of the observational record and the assumptions of extreme value theory (Sanabria and Cechet, 2010).

Particular gaps arise concerning the occurrence of widespread damaging 
convective wind events caused by squall lines or derechos (Corfidi et al., 2015) and other observed damaging convective wind events outside of NSW and southeast QLD. Exploring other approaches to leverage and extend observations (e.g Foley and Hanstrum, 1990) from the Bureau STA is another approach to improve our understanding of these events. Given the wide array of environments favorable to damaging convective winds, this also suggests the need to explore environmental climatology of these conditions over the continent to understand the risk.

\section{Forecasting}

To describe the full responsibilities of the meteorologists that staff Australian regional severe weather desks would be cumbersome in the context of this review, so hence here we focus on the research conducted to build tools to inform this system and refer readers to Deslandes et al. (2008) for further details, while discussing the limitations in our understanding for forecast guidelines and the current warning process.

Guidance at the outlook period for severe thunderstorm forecasters in Australia (Deslandes et al., 2008) was developed using a decision tree algorithm that has been extended from its initial inception in 1987 to be applied as an automated severe thunderstorm threat assessment from regional numerical weather prediction (Colquhoun, 1987; Mills and Colquhoun, 1998). The algorithm relies on a set of derived environmental relationships used to discriminate at each level of the decision tree, primarily based on instability and VWS, applying the latest parameters identified as useful for forecasting in the U.S. and locally. This approach provides an automated analysis that is equivalent to severe thunderstorm watch guidance (Mills and Colquhoun, 1998; Mills, 2004). One limitation of this approach however, were the relatively small samples (e.g. of supercell thunderstorms) used to determine some of the decision criteria in subsequent iterations (e.g. Treloar and Hanstrum, 2002), and a limited testing period prior to implementation (Mills and Colquhoun, 1998). These limitations suggest a need for more extensive climatology and larger samples to develop forecasting guidelines, particularly for events which do not conform to the existing forecasting decision tree.

In addition to the need to explore and revise guidelines for the various elements of severe thunderstorm environment applications and sub-cases, there are also limitations to the existing warning and nowcasting processes (Deslandes et al., 2008; Allen et al., 2016). Despite operationally now having 
the Doppler radar network along with tools and radar-algorithms to issue cell-based warnings (Fox et al., 2004; Joe et al., 2004; Wilson et al., 2004; SREP, 2015) outside of the state capitals, public warnings similar to watches are issued for several hours on a state-wide basis (Figure 10). Following this step, little to no guidance is provided to the rural public to warn of particularly intense or dangerous cells such as supercells, in contrast to the major centers. This problem is further exacerbated by few verifications of forecasts and evaluations of the warning process, and compounded by insufficient severe thunderstorms observations to perform an appropriate analysis. Even over the major centers, there are some elements of public confusion regarding the implications of the issued warnings, for example if they are referring to a rainfall hazard or severe thunderstorm phenomena such as hail, or damaging convective wind gusts. A further ongoing issue is the lack of flexibility to issue tornado warnings without visual confirmation, despite the recent availability of a considerable network of $19 \mathrm{~S}$ or C-band Doppler radar sites (Sills et al., 2004; SREP, 2015; Allen et al., 2016).

\section{Climate Change and Natural Variability}

\subsection{Climate Variability}

There are a number of climate signals that contribute to natural variability in severe thunderstorm occurrence around the globe (Tippett et al., 2015). It is important to note however that establishing such relationships is made challenging by the limitations of observed records, and often requires the use of environmental proxies to establish a robust signal (e.g. Allen et al., 2015b). The largest contribution to interannual variability worldwide comes from ENSO, which also has a significant impact on the moisture available over southeast Australia. This leads to strong relationships with severe thunderstorm activity, though there are regional variations in the observed signal. Over the Sydney region, hailstorm activity is strongly enhanced during La Niña, or rising Southern Oscillation Index (SOI) between July to November (Kuhnel, 1998; Leigh and Kuhnel, 2001). In contrast, neutral ENSO conditions are considerably more active for severe thunderstorm days over southeast QLD, while El Niño provides the second most favorable scenario (Yeo, 2005). Analyzing proxy severe thunderstorm environments, Allen and Karoly (2014) identified that neutral ENSO conditions produced the greatest number of favorable severe thunderstorm environments across the continent and east coast (Figure 6). The largest spatial changes however were instigated by 
the available moisture during La Niña, which produces a larger area of favorable environments south and inland over the east coast (Figure 11a). During El Niño, there is an increase in frequency over the southwest of the continent, and a northward shift over the east coast related to differences in moisture availability (Figure 11b). However, this simple analysis of the influence of the ENSO signal reveals that this climate signal explains only part of the variability of severe thunderstorm events over Australia. This suggests the need for further study to explore other locally relevant potential contributions to variability such as local sea-surface temperatures (Allen and Karoly, 2014), land cover changes (Gero and Pitman, 2006), the Madden-Julian Oscillation (Barrett and Gensini, 2013), the Indian Ocean Dipole (Webster et al., 1999) and contributions from decadal variability (Mantua et al., 1997).

\subsection{Climatic Change}

Investigations over the U.S. and Europe have established that despite insufficient observational or proxy evidence to identify conclusive trends in 20th century severe thunderstorm occurrence, a warming climate is simulated to lead to an increased frequency of severe thunderstorm favorable environments, primarily driven by an increase in CAPE (Trapp et al., 2007; Brooks, 2013; Tippett et al., 2015; Diffenbaugh et al., 2013). On this basis we direct the reader to consider a global analysis of this question for a more general discussion (Brooks, 2013; Tippett et al., 2015), and here we focus on the regional implications for Australia, given that a similar lack of trend outside of natural variability is seen in both the frequency of thunderdays and environmental climatology (Figure 6) for the past three decades (Davis and Walsh, 2008; Allen and Karoly, 2014).

Early analysis of primitive and coarse resolution global climate model simulations for Australia suggested decreases in the frequency of hail (McMaster, 1999). These results were supported by later projections using the CSIRO Mk3 model which suggested decreases in the number of days with sufficient CAPE for severe hail, and an increase in the intensity of hail events when they do occur for two stations in southeast Australia (Niall and Walsh, 2005). Over the Sydney basin, high resolution simulations identified that favorable CAPE pre-storm environments were expected to increase in association with rising surface temperatures and dewpoints, leading to increasing severity in large hail events despite reduced frequency (Leslie et al., 2008). These results were consistent with a simulation over the continent Abbs et al. 
(2007), which suggested a doubling in the frequency of days with environments favorable to severe hail over NSW, despite the model overestimating frequency over the remainder of the southeast.

In the most recent analysis of the impacts of climate change on Australian severe thunderstorms Allen et al. (2014a) assessed the performance of two global climate models (CSIRO Mk3.6 and the Cubic-Conformal Atmospheric Model or CCAM) to represent convective parameters in the present climate by comparing with reanalysis climatology. This analysis revealed a strong degree of sensitivity in severe thunderstorm environments to model physics, particularly relating to moisture advection and convective parameterizations. Contributing to these issues were considerable differences in the height of east coast topography as a result of horizontal resolution, with peak terrain heights in CSIRO Mk3.6 limited to $400 \mathrm{~m}$, contrasting $1200 \mathrm{~m}$ for CCAM, leading to large differences in moisture advection from the Tasman and Coral Seas. CSIRO Mk3.6 also struggled in resolving the diurnal cycle of occurrence, and, in each aspect the higher resolution CCAM was found to be conservative but offer a more accurate representation of the actual climatology. Taking into account these model limitations, Allen et al. (2014b) explored future projections for 2079-2099 under highly warmed future climate scenarios. In a warming climate, severe thunderstorm environments increased in frequency, particularly over the east coast (Figure 12). Statistically significant increases in occurrence for Brisbane, Sydney and Melbourne were $15 \%, 30 \%$ and $22 \%$ respectively of 20 th century values. Changes were found to be strongly sensitive to the model considered, particularly as a function of topography and its resulting influence on advection, but in both cases proximity to higher sea-surface temperatures and advected moisture increased the frequency of high CAPE environments in a warmed world. In contrast, high S06 frequency decreased with poleward shift of the jetstream, but did not outweigh the contribution of increases to the thermodynamic energy available to the atmosphere, consistent with the international and prior regional results (e.g. Diffenbaugh et al., 2013).

A consideration that has not been explored globally concerns the influence of warming on cool-season tornadoes which form in low-instability environments (Kounkou et al., 2007). These events, unlike their warm season counterparts, have been suggested to be less likely because of thermal stabilization of the lower troposphere during the winter months (Timbal et al., 2010), however further research is needed to explore these potential signals in more detail. 
Despite recent work that better quantifies the influence of a warming climate on severe thunderstorms in Australia, the body of research remains limited. A number of questions remain unanswered relating to the need to consider a larger suite of model output for analyzing the potential change given large differences between models, how to interpret estimations of initiation of these events in the future, and the importance of model physics and topographical features to the severe thunderstorm environment in Australia. Several options also exist to explore dynamical downscaling approaches such as those applied by Gensini and Mote (2015) over the U.S. to directly simulate storm occurrence rather than favorable environments. Also unaddressed, and spurred by the lack of observations or proxy climatologies, are estimates of how hail, tornadoes and damaging convective winds respectively may respond to a warming climate.

\section{Discussion and Future Directions}

Based on the literature reviewed, it would appear that no capital city of Australia is immune to the risk severe thunderstorm impacts, and much of the continent has a relatively high rate of exposure. The formation mechanisms can widely vary for each of the phenomena over the continent, and in doing so can mean that their occurrence may be unexpected. As noted by Middlemann et al. (2007) insufficient observational records for each of the primary hazards associated with severe thunderstorms are a primary limiting factor in determining risk, though alternate approaches using environmental proxies, satellite-derived climatologies and radar-derived records are becoming available to compensate for these limitations. This is accompanied by a disconnect to the resulting vulnerability in communities and the natural environment. Thus even with an adequate profile of risk, further research is necessary to understand the impacts of near-surface damaging winds from convective storm events or tornadoes, and the impacts of hail on agriculture and the built environment (Middlemann et al., 2007).

The relative infrequency of recent case studies and evaluation of forecasts for verification also highlights the need increased scrutiny of recent events to identify characteristics that can improve the nowcasting and forecast knowledge for the continent. This can partly be explained by the relatively small severe storm community in Australia at the current juncture, which results in relatively few active research projects in the subject area. Examples of ongoing work include exploring the climatology of hail using radar data sim- 
ilar to the approach of Cintineo et al. (2012) (H. Ramsay, pers. comm.), the use of portable and fixed radars to study the climatology of thunderstorm initiation and structure of storms in the Brisbane region (Soderholm et al., 2016), efforts to extend the observational database of hail and tornadoes (Allen and Allen, 2014; Allen et al., 2016) as well as ongoing case studies and efforts to extending forecasting guidance by operational/support meteorologists (Richter, 2014a,b). The recent expansion of the Doppler radar network (SREP, 2015) to 19 Doppler capable S- or C-band sites across the country will play a critical role in the near future, as it allows an enhanced ability to warn the general public, along with promoting increased remotely-sensed observations from which to explore the characteristics and climatology of severe storms in Australia.

Specific directions that present opportunity for future research include:

- A greater utilization of the implemented Doppler radar network and potentially satellite data to provide a basis for case studies for significant events, to improve the warning process and for post-event climatological identification similar to the efforts of Cintineo et al. (2012) and expanding the work of Soderholm et al. (2016).

- A need for observational climatology to be revisited and extended by leveraging both local knowledge and digitized written records. One such example currently underway is the Australian Tornado Project (Allen and Allen, 2014) which applies National Library Archive data to identify historical tornadoes, and has been incredibly successful in extending this dataset (Figure 9).

- A greater application of numerical model and reanalysis data to understand the environmental conditions leading to severe thunderstorms in Australia. This direction acts to both enhance the knowledge of climatology, but also provide forecasting guidelines to operational meteorologists to improve the overall hazard detection process.

- A need to pursue a greater understanding of the impacts of climate variability and change on severe thunderstorms and their climatology. While several of the above noted directions suggest that producing a climatology of occurrence will require considerable effort, there is a need to take this step and understand what the changes to risk are as a response to either a warming climate, or climate signals such as ENSO. 
- Consideration of a cell-based warning system outside of the major capital cities to improve the efficacy of warning for severe thunderstorms, and whether a separate category for tornado warnings similar to those applied in the U.S. (Brotzge and Donner, 2013) may be appropriate given increasing understanding of the risk.

- Improved understanding of the vulnerability and losses due to severe thunderstorm hazards. This includes using these insights for the built and natural environments to inform enhancements to subsequent climatological risk assessments and thereby increase resilience of the population to the impacts of these events.

\section{Conclusions}

There remain a number of significant gaps in our understanding of severe thunderstorms over Australia, and the risks they entail for the general public and the built environment. A groundwork has been laid in many of the relevant areas to begin to better understand the hazard, stretching from observational climatologies to proxy-derived frequency assessments, numerous case studies, and applications to climate change and variability. The existing work however has numerous limitations that are ripe to be addressed using modern resources and techniques to extend our understanding of the climatology and improve forecasting of these events. Numerous opportunities also exist to better understand why one year may be more active for severe thunderstorms than another, and assess how this may change into the future. Along with the relatively small research community, the limited research resources available for this topic further exacerbates the gaps in existing knowledge. This suggests that an opportunity is present to support further fundamental research into understanding the damaging potential of severe thunderstorms over the continent.

\section{Acknowledgements}

The basis for this paper began as a review of the literature during $\mathrm{J}$. Allen's Ph.D. research on severe thunderstorms in Australia. Both authors equally contributed to the review of literature, writing and editing process. The authors are grateful to a number of individuals over the years who have discussed the history and literature of severe storms in Australia with them: 
Graham Mills, Harald Richter, Harold Brooks, David Karoly and Kevin Walsh. We also acknowledge the permission to use the figures of Andrew Dowdy and Joshua Soderholm from their respective publications, and the Bureau of Meteorology for freely providing the national severe thunderstorm archive. J Allen acknowledges support from U.S. Office of Naval Research (N00014-12-1-0911) in preparing this manuscript. Finally we acknowledge the support of the editors of Atmospheric Research for encouraging preparation of this review.

\section{References}

Abbe, C., 1906. Tornadoes in Australia. Mon. Wea. Rev. 34, 227-228.

Abbs, D., Timbal, B., Rafter, A., Walsh, K., 2007. Severe weather. Climate Change in Australia: Technical Report 2007, 102-106.

Allen, J., 2012. Supercell storms: Melbournes white Christmas 2011. Bull. Aust. Meteor. Oceanogr. Soc 25, 47-51.

Allen, J. T., Allen, E. R., 2014. The tornado climatology of Australia 17952013. In: 27th AMS Conference on Severe Local Storms, Madison, Wisconsin.

Allen, J. T., Allen, E. R., Richter, H., 2016. An analysis of Australian tornadoes in 2013. Aust. Meteor. Oceanogr. Jour. In Preparation.

Allen, J. T., Karoly, D. J., 2014. A climatology of Australian severe thunderstorm environments 1979-2011: Inter-annual variability and ENSO influence. Int. J. Climatol. 34, 81-97.

Allen, J. T., Karoly, D. J., Mills, G. A., 2011. A severe thunderstorm climatology for Australia and associated thunderstorm environments. Aust. Meteor. Oceanogr. Jour. 61, 143-158.

Allen, J. T., Karoly, D. J., Walsh, K. J., 2014a. Future Australian severe thunderstorm environments. Part I: A novel evaluation and climatology of convective parameters from two climate models for the late twentieth century. J. Climate 27, 3827-3847. 
Allen, J. T., Karoly, D. J., Walsh, K. J., 2014b. Future Australian severe thunderstorm environments. Part II: The influence of a strongly warming climate on convective environments. J. Climate 27, 3848-3868.

Allen, J. T., Tippett, M. K., 2015. The characteristics of United States Hail Reports: 1955-2014. Electron. J. Severe Storms Meteorol. In Press.

Allen, J. T., Tippett, M. K., Sobel, A. H., 2015a. An empirical model relating u.s. monthly hail occurrence to large-scale meteorological environment. J. Adv. Modelling Earth Sys. 7, 226-243.

Allen, J. T., Tippett, M. K., Sobel, A. H., 04 2015b. Influence of the El Nino/Southern Oscillation on tornado and hail frequency in the United States. Nat. Geosci 8, 278-283.

Allen, S., 1980. A preliminary Australian tornado climatology. Bureau of Meteorology, 15pp.

Andrews, K. E., Blong, R. J., 1997. March 1990 hailstorm damage in sydney, australia. Natural Hazards 16, 113-125.

Australian Bureau of Statistics, 2001. Census of population and housing: Population growth and distribution, australia, cat. no. 2035.0. available at: http://www.abs.gov.au/ausstats/abs@.nsf/lookup/2035.0main+features12 001?opendocument Accessed: October 21st 2015.

Australian Bureau of Statistics, 2008. Census of population and housing: Population growth and distribution, australia, cat. no. 2035.0. available at: http://www.abs.gov.au/ausstats/abs@.nsf/7d12b0f6763c78caca257061001 cc588/00408ced366bb56aca2570de00029f46!opendocument Accessed: October 21st 2015.

Barnes, G., 2001. Severe local storms in the tropics. In: Severe Convective Storms. Springer, pp. 359-432.

Barrett, B. S., Gensini, V. A., 2013. Variability of central United States April-May tornado day likelihood by phase of the Madden-Julian Oscillation. Geophys. Res. Lett. 40, 2790-2795.

Bhaskaran, S., Forster, B., Datt, B., Neal, T., 2001. Hail storm vulnerability assessment by using hyperspectral remote sensing and gis techniques. In: 
Geoscience and Remote Sensing Symposium, 2001. Vol. 4. IEEE, pp. 18261828.

Blair, S. F., Deroche, D. R., Boustead, J. M., Leighton, J. W., Barjenbruch, B. L., Gargan, W. P., 2011. A radar-based assessment of the detectability of giant hail. Electron. J. Severe Storms Meteorol. 6, 1-30.

Blong, R., 2005. Natural hazards risk assessment: an Australian perspective. Issues in Risk Science 4. Benfield Hazard Research Centre. London. pp. 28.

BOM, 2015. Bureau of Meteorology Severe Thunderstorm Archive. Available at: http://www.bom.gov.au/australia/stormarchive/ Accessed: 25th November 2015.

Brooks, H. E., 2009. Proximity soundings for severe convection for Europe and the United States from reanalysis data. Atmos. Res. 93, 546-553.

Brooks, H. E., 2013. Severe thunderstorms and climate change. Atmos. Res. 123, 129-138.

Brooks, H. E., Doswell, III, C. A., 2001. Some aspects of the international climatology of tornadoes by damage classification. Atmos. Res. 56, $191-$ 201.

Brooks, H. E., Dotzek, N., 2007. The spatial distribution of severe convective storms and an analysis of their secular changes. In: Diaz, H. F., Murnane, R. (Eds.), Climate Extremes and Society. Cambridge University Press, New York, pp. 35-54.

Brooks, H. E., Lee, J. W., Craven, J. P., 2003. The spatial distribution of severe thunderstorm and tornado environments from global reanalysis data. Atmos. Res. 67-68, 73-94.

Brotzge, J., Donner, W., 2013. The tornado warning process: A review of current research, challenges, and opportunities. Bull. Am. Meteor. Soc. 94, $1715-1733$.

Buckley, B. W., Leslie, L. M., Wang, Y., 2001. The sydney hailstorm of april 14, 1999: Synoptic description and numerical simulation. Meteor. Atmos. Phys. 76, 167-182. 
Buckley, B. W., Sullivan, W., Chan, P., Leplastrier, M., 2010. Two record breaking australian hail storms: storm environments, damage characteristics and rarity. In: 25th Conference on Severe Local Storms, Denver, Colorado.

Byers, H. R., Braham, R. R., 1949. The thunderstorm: Report of the Thunderstorm Project. US Government Printing Office.

Cechet, R., Sanabria, L., Divi, C., Thomas, C., Yang, T., Arthur, W., Dunford, M., Nadimpalli, K., Power, L., White, C., et al., 2012. Climate futures for tasmania: Severe wind hazard and risk, pp. 88.

Cecil, D. J., Blankenship, C. B., 2012. Toward a global climatology of severe hailstorms as estimated by satellite passive microwave imagers. J. Climate 25, 687-703.

Cintineo, J. L., Smith, T. M., Lakshmanan, V., Brooks, H. E., Ortega, K. L., 2012. An objective high-resolution hail climatology of the contiguous United States. Wea. Forecasting 27, 1235-1248.

Clarke, R. H., 1962. Severe local wind storms in Australia. No. 13. Commonwealth Scientific and Industrial Research Organization, Australia.

Coates, L., Blong, R., Siciliano, F., 1993. Lightning fatalities in Australia, 1824-1991. Natural Hazards 8, 217-233.

Colquhoun, J., 1987. A decision tree method of forecasting thunderstorms, severe thunderstorms and tornadoes. Wea. Forecasting 2, 337-345.

Colquhoun, J., 1995. The Sydney supercell thunderstorm? Weather 50 (1), $15-18$.

Corfidi, S. F., Coniglio, M. C., Cohen, A. E., Mead, C. M., 2015. A proposed revision to the definition of derecho. Bull. Am. Meteor. Soc. In Press.

Cremer, K., 1984a. Hail damage in Australian pine plantations i. nature and extent of damage. Aust. Forestry 47, 103-114.

Cremer, K., 1984b. Nature and impact of damage by wind, hail and snow in Australia's pine plantations. Aust. Forestry 47, 28-38. 
Crompton, R. P., McAneney, K. J., 2008. Normalised Australian insured losses from meteorological hazards: 1967-2006. Env. Science \& Policy 11, $371-378$.

Cunningham, P., Reeder, M. J., 2009. Severe convective storms initiated by intense wildfires: Numerical simulations of pyro-convection and pyrotornadogenesis. Geophys. Res. Lett. 36, L12812.

Davis, S., Walsh, K., 2008. Southeast australian thunderstorms: are they increasing in frequency? Aust. Met. Mag. 57, 1-11.

Day, D., 2007. The weather watchers: 100 years of the Bureau of Meteorology. Melbourne University Press, pp. 530.

Deslandes, R., Richter, H., Bannister, T., 2008. The end-to-end severe thunderstorm forecasting system in australia: overview and training issues. Aust. Met. Mag. 57 (4).

Diffenbaugh, N. S., Scherer, M., Trapp, R. J., 09 2013. Robust increases in severe thunderstorm environments in response to greenhouse forcing. Proc. Natl. Acad. Sci. (USA) 101, 16361-16366.

Doswell, C. A., 1987. The distinction between large-scale and mesoscale contribution to severe convection: A case study example. Wea. Forecasting 2, $3-16$.

Doswell, C. A., Brooks, H., 1993. Supercell thunderstorms. Weather 48, 209 210.

Doswell, III, C. A., 2001. Severe convective storms - an overview. Meteorological Monographs 28 (50), 1-26.

Doswell, III, C. A., Brooks, H. E., Kay, M. P., 2005. Climatological estimates of daily local nontornadic severe thunderstorm probability for the United States. Wea. Forecasting 20, 577-595.

Doswell, III, C. A., Brooks, H. E., Maddox, R. A., 1996. Flash flood forecasting: An ingredients-based methodology. Wea. Forecasting 11, 560-581.

Dotzek, N., Groenemeijer, P., Feuerstein, B., Holzer, A. M., 2009. Overview of ESSL's severe convective storms research using the European Severe Weather Database ESWD. Atmos. Res. 93, 575-586. 
Dowdy, A. J., Kuleshov, Y., 2014. Climatology of lightning activity in Australia: spatial and seasonal variability. Aust. Meteor. Oceanogr. Jour. 6, $9-14$.

Dowdy, A. J., Mills, G. A., 2012. Atmospheric and fuel moisture characteristics associated with lightning-attributed fires. J. Appl. Meteor. Climatol. 51, 2025-2037.

Edwards, R., 2012. Tropical cyclone tornadoes: A review of knowledge in research and prediction. Electron. J. Severe Storms Meteorol. 7.

Evesson, D., 1970. Tornado occurrences in New South Wales. Aust. Met. Mag. 17, 143-165.

Eyre, L., 1992. How severe can a severe thunderstormbe?: An investigation into two violent electrical storms in australia. Weather 47, 374-383.

Ferraro, R., Beauchamp, J., Cecil, D., Heymsfield, G., 2015. A prototype hail detection algorithm and hail climatology developed with the advanced microwave sounding unit (AMSU). Atmos. Res. 163, 24-35.

Foley, G., Hanstrum, B., 1990. Severe local wind storms over southwest western australia during the cooler months. In: Proc. Second Australian Severe Thunderstorm Workshop. pp. 1-28.

Fox, N. I., Webb, R., Bally, J., Sleigh, M. W., Pierce, C. E., Sills, D. M., Joe, P. I., Wilson, J., Collier, C. G., 2004. The impact of advanced nowcasting systems on severe weather warning during the Sydney 2000 Forecast Demonstration Project: 3 November 2000. Wea. Forecasting 19, 97-114.

Fromm, M., Tupper, A., Rosenfeld, D., Servranckx, R., McRae, R., 2006. Violent pyro-convective storm devastates Australia's capital and pollutes the stratosphere. Geophys. Res. Lett. 33, L05815.

Fujita, T. T., 1973. Tornadoes around the world. Weatherwise 26, 56-83.

Geerts, B., 2001. Estimating downburst-related maximum surface wind speeds by means of proximity soundings in New South Wales, Australia. Wea. Forecasting 16, 261-269.

Geerts, B., Noke-Raico, M., 1995. Tornadoes in Australia: Do we really know? Bull. Aust. Meteor. Oceanogr. Soc 8, 46-51. 
Gensini, V. A., Mote, T. L., 2015. Downscaled estimates of late 21st century severe weather from ccsm3. Climate Change 129, 307-321.

Gero, A., Pitman, A., 2006. The impact of land cover change on storms in the sydney basin, australia. Global Planet. Change 54, 57-78.

Goliger, A., Milford, R., 1998. A review of worldwide occurrence of tornadoes. J. Wind Engineering Industrial Aerodynamics 74, 111-121.

Grams, J. S., Thompson, R. L., Snively, D. V., Prentice, J. A., Hodges, G. M., Reames, L. J., 2011. A climatology and comparison of parameters for significant tornado events in the United States. Wea. Forecasting 27, $106-123$.

Grazulis, T. P., 1993. Significant tornadoes 1680-1991: A chronology and analysis of events.

Griffiths, D., Colquhoun, J., Batt, K., Casinader, T., 1993. Severe thunderstorms in new south wales: climatology and means of assessing the impact of climate change. Climate Change 25, 369-388.

Hales, J. E., 1993. Biases in the severe thunderstorm data base: Ramifications and solutions. In: Preprints, 13th Conf. on Weather Forecasting and Analysis, Vienna, VA, Amer. Meteor. Soc. pp. 504-507.

Hand, W. H., Cappelluti, G., 2011. A global hail climatology using the uk met office convection diagnosis procedure (CDP) and model analyses. Meteor. Appl. 18, 446-458.

Hanstrum, B., Foley, G., 1990. A diagnostic case study of the thunderstorm event of 8 November 1986 at Perth, Western Australia. Aust. Met. Mag. $38,271-279$.

Hanstrum, B. N., Mills, G. A., Watson, A., Monteverdi, J. P., Doswell, III, C. A., 2002. The cool-season tornadoes of California and Southern Australia. Wea. Forecasting 17, 705-722.

Harper, B., Granger, K., Hall, S., 2000. Severe thunderstorm risks. In: Natural Hazards and the Risks they Pose to South-East Queensland. Australian Geological Survey Organisation, pp. 11. 
Holcombe, G., Moynihan, G., 1978. An investigation of the Brisbane tornado of 4 November 1973. Bureau of Met. Australia Met. Note 97.

Holmes, J. D., 2002. A re-analysis of recorded extreme wind speeds in region a. Aust. J. Structural Engineering 4, 29.

Houston, W., 1999. Severe hail damage to mangroves at Port Curtis, Australia. Mangroves and Salt Marshes 3, 29-40.

Hunt, H., W.J., H., 1927. Australian vs American tornado frequency. Bull. Am. Meteor. Soc. 8, 46-47,128-129.

Joe, P., Burgess, D., Potts, R., Keenan, T., Stumpf, G., Treloar, A., 2004. The S2K severe weather detection algorithms and their performance. Wea. Forecasting 19, 43-63.

Kelly, D. L., Schaefer, J. T., Doswell III, C. A., 1985. Climatology of nontornadic severe thunderstorm events in the United States. Mon. Wea. Rev. 113, 1997-2014.

Kounkou, R., Mills, G., Timbal, B., 2009. A reanalysis climatology of coolseason tornado environments over southern Australia. Int. J. Climatol. 29, 2079-2090.

Kounkou, R., Mills, G. A., Timbal, B., 2007. The impact of anthropogenic climate change on the risk of cool-season tornado occurrences. Issue 129, BMRC research report, pp. 72 .

Kuhnel, I., 1998. The use of a multifactor Southern Oscillation Index for the estimation of annual hailstorm frequencies in the Sydney area. Int. J. Climatol. 18, 841-858.

Kuleshov, Y., 2004. Seasonal and latitudinal variations of lightning ground flash activity in Australia. Aust. Met. Mag. 53, 197-204.

Kuleshov, Y., De Hoedt, G., Wright, W., Brewster, A., 2002. Thunderstorm distribution and frequency in Australia. Aust. Met. Mag. 51, 145-154.

Kuleshov, Y., Jayaratne, E., 2004. Estimates of lightning ground flash density in Australia and its relationship to thunder-days. Aust. Met. Mag. 53, 189196. 
Kuleshov, Y., Mackerras, D., Darveniza, M., 2006. Spatial distribution and frequency of lightning activity and lightning flash density maps for Australia. J. Geophys. Res. 111, D19105.

Kuleshov, Y., Mackerras, D., Darveniza, M., 2009. Spatial distribution and frequency of thunderstorms and lightning in australia. In: Betz, H., Schumann, U., Laroche, P. (Eds.), Lightning: Principles, Instruments and Applications. Springer, pp. 187-207.

Leigh, R., Kuhnel, I., 2001. Hailstorm loss modelling and risk assessment in the Sydney region, Australia. Natural Hazards 24, 171-185.

Leslie, L. M., Leplastrier, M., Buckley, B. W., 2008. Estimating future trends in severe hailstorms over the Sydney Basin: A climate modelling study. Atmos. Res. 87, 37-51.

Mantua, N. J., Hare, S. R., Zhang, Y., Wallace, J. M., Francis, R. C., 1997. A Pacific interdecadal climate oscillation with impacts on salmon production. Bull. Am. Meteor. Soc. 78, 1069-1079.

Matthews, C., Geerts, B., 1995. Characteristic thunderstorm distribution in the Sydney area. Aust. Met. Mag. 44, 127-138.

McMaster, H., 1999. The potential impact of global warming on hail losses to winter cereal crops in New South Wales. Climatic Change 43, 455-476.

McMaster, H., 2001. Hailstorm risk assessment in rural New South Wales. Natural Hazards 24, 187-196.

McRae, R. H., Sharples, J. J., Wilkes, S. R., Walker, A., 2013. An Australian pyro-tornadogenesis event. Natural hazards 65, 1801-1811.

Melaragno, M. G., 1976. Structural design and Australian tornadoes. Architectural Sci. Rev. 19, 78-83.

Middlemann, M. H., Middelmann, M., Australia, G., 2007. Natural hazards in Australia: identifying risk analysis requirements. Geoscience Australia.

Mills, G., Colquhoun, J., 1998. Objective prediction of severe thunderstorm environments: Preliminary results linking a decision tree with an operational regional NWP model. Wea. Forecasting 13, 1078-1092. 
Mills, G. A., 2004. Verification of operational cool-season tornado threat-area forecasts from mesoscale NWP and a probabilistic forecast product. Aust. Met. Mag. 53, 269-277.

Minor, J. E., Peterson, R. E., Lourensz, R., 1980. Characteristics of Australian tornadoes. Aust. Met. Mag. 28, 57-77.

Munich RE, 2015. Severe convective storms and hail - icy cricket balls from above, available at: http://www.munichre.com/australia/australianatural-hazards/australia-storm/hailstorm/index.html, accessed on 25th november 2015.

Myers, B. J., 1984. Hail damage in Australian pine plantations ii. aerial photographic techniques for mapping the damage. Aust. forestry 47, 115118.

Newman, B., 1947. Phenomenal hailstorm with thunderstorm Sydney, 1st January 1947. Wea. Res. Dev. Bull. 8, 23-41.

Niall, S., Walsh, K., 2005. The impact of climate change on hailstorms in southeastern Australia. Int. J. Climatol. 25, 1933-1952.

Peterson, R. E., Minor, J. E., Golden, J. H., Scott, A., 1979. A rare close up of an Australian tornado. Weatherwise 32, 188-193.

Phillips, E., 1965. The Nurmurkah tornado of august 1964. Aus. Met. Mag. 48, 37-45.

Plukss, A., 1979. The tornadoes of 13 November 1976 in Victoria with particular reference to the Sandon area. Bureau of Met. Australia Met. Note 101, 16pp.

Punge, H. J., Bedka, K. M., Kunz, M., Werner, A., 2014. A new physically based stochastic event catalog for hail in Europe. Natural Hazards 73, $1625-1645$.

Rasmussen, E. N., Blanchard, D. O., 1998. A baseline climatology of sounding-derived supercell andtornado forecast parameters. Wea. Forecasting 13, 1148-1164.

Rasmusson, E. M., Wallace, J. M., 1983. Meteorological aspects of the El Nino/Southern Oscillation. Science 222, 1195-1202. 
Richter, H., 2014a. The Australian National Thunderstorm Forecast Guidance System: New calibrated ensemble-based total thunderstorm probabilities. CAWCR Res. Lett. 11, 20-25.

Richter, H., 2014b. Calibrated thunderstorm probabilities over australia derived from two 5-member lag ensembles. In: 27th AMS Conference on Severe Local Storms, Madison, Wisconsin.

Richter, H., Peter, J., Collis, S., 2014. Analysis of a destructive wind storm on 16 november 2008 in brisbane, australia. Mon. Wea. Rev. 142, 3038-3060.

Russell, H., 1889. Windstorm at Sydney NSW. Quart. J. Roy. Meteor. Soc. 15, 191-192.

Russell, H., 1891. A cyclonic storm or tornado in the Gwydir district. J. Roy. Soc., New South Wales 25, 58-60.

Russell, H., 1893. Hail storms. Nature 47, 573-574.

Ryan, C., 1992. Dynamical classification of Australian thunderstorms, Meteorological Study No. 40, Bureau of Meteorology.

Sanabria, L., Cechet, R., 2010. Severe wind hazard assessment using Monte Carlo simulation. Env. Modeling \& Assessment 15, 147-154.

Schuster, S., Blong, R., Leigh, R., McAneney, K., 2005a. Characteristics of the 14 April 1999 Sydney hailstorm based on ground observations, weather radar, insurance data and emergency calls. Natural Hazards and Earth System Science 5, 613-620.

Schuster, S. S., Blong, R. J., McAneney, K. J., 2006. Relationship between radar-derived hail kinetic energy and damage to insured buildings for severe hailstorms in Eastern Australia. Atmos. Res. 81, 215-235.

Schuster, S. S., Blong, R. J., Speer, M. S., 2005b. A hail climatology of the greater Sydney area and New South Wales, Australia. Int. J. Climatol. 25, $1633-1650$.

Sills, D. M., Wilson, J. W., Joe, P. I., Burgess, D. W., Webb, R. M., Fox, N. I., 2004. The 3 november tornadic event during Sydney 2000: Storm evolution and the role of low-level boundaries. Wea. Forecasting 19, 22-42. 
Soderholm, J., McGowan, H., Richter, H., Walsh, K., Weckwerth, T., Coleman, M., 2016. The Coastal Convective Interactions Experiment (CCIE): Understanding the role of sea breezes for hailstorm hotspots in Eastern Australia. Bull. Am. Meteor. Soc. In Press.

Southern, R., 1960. Study of a tornado situation in south-west australia. Aus. Met. Mag 31, 1-12.

SREP, 2015. Bureau of Meteorology Strategic Radar Enhancement Project. Available at: http://www.bom.gov.au/australia/radar/about/srep.shtml Accessed: 25th November 2015.

Thompson, R. L., Smith, B. T., Grams, J. S., Dean, A. R., Broyles, C., 2012. Convective modes for significant severe thunderstorms in the contiguous United States. Part II: Supercell and QLCS tornado environments. Wea. Forecasting 27, 1136-1154.

Timbal, B., Kounkou, R., Mills, G., 2010. Changes in the risk of cool-season tornadoes over southern Australia due to model projections of anthropogenic warming. J. Climate 23, 2440-2449.

Tippett, M. K., Allen, J. T., Gensini, V. A., Brooks, H. E., 2015. Climate and hazardous convective weather. Current Climate Change Reports 1, 60-73.

Trapp, R. J., Diffenbaugh, N. S., Brooks, H. E., Baldwin, M. E., Robinson, E. D., Pal, J. S., 2007. Changes in severe thunderstorm environment frequency during the 21st century caused by anthropogenically enhanced global radiative forcing. Proc. Natl. Acad. Sci. (USA) 104, 19719-19723.

Trapp, R. J., Wheatley, D. M., Atkins, N. T., Przybylinski, R. W., Wolf, R., 2006. Buyer beware: Some words of caution on the use of severe wind reports in postevent assessment and research. Wea. Forecasting 21, 408415.

Treloar, A., Hanstrum, B., 2002. A study of australian warm season supercell thunderstorms. In: Weather Services Scientific Conference. pp. 99-100.

Tucker, D. F., 2002. Characteristics of severe hail events in eastern australia. In: 21st Conference on Severe Local Storms, San Antonio, Texas, American Meteorological Society. pp. 91-94. 
Wakimoto, R. M., 2001. Convectively driven high wind events. In: Severe Convective Storms. Springer, pp. 255-298.

Wang, C.-H., Wang, X., Khoo, Y. B., 2013. Extreme wind gust hazard in Australia and its sensitivity to climate change. Natural hazards 67, 549567.

Webster, P. J., Moore, A. M., Loschnigg, J. P., Leben, R. R., 1999. Coupled ocean-atmosphere dynamics in the Indian Ocean during 1997-98. Nature 401, 356-360.

Wilson, J. W., Ebert, E. E., Saxen, T. R., Roberts, R. D., Mueller, C. K., Sleigh, M., Pierce, C. E., Seed, A., 2004. Sydney 2000 forecast demonstration project: convective storm nowcasting. Wea. Forecasting 19, 131-150.

Yeo, C. S., 2005. Severe thunderstorms in the Brisbane region and a relationship to the El Niño Southern Oscillation. Aust. Met. Mag. 54, 197.

Yeo, S., Leigh, R., Kuhnel, I., 1999. The April 1999 Sydney hailstorm. Aust. Journal Emer. Management 5, 23-25. 


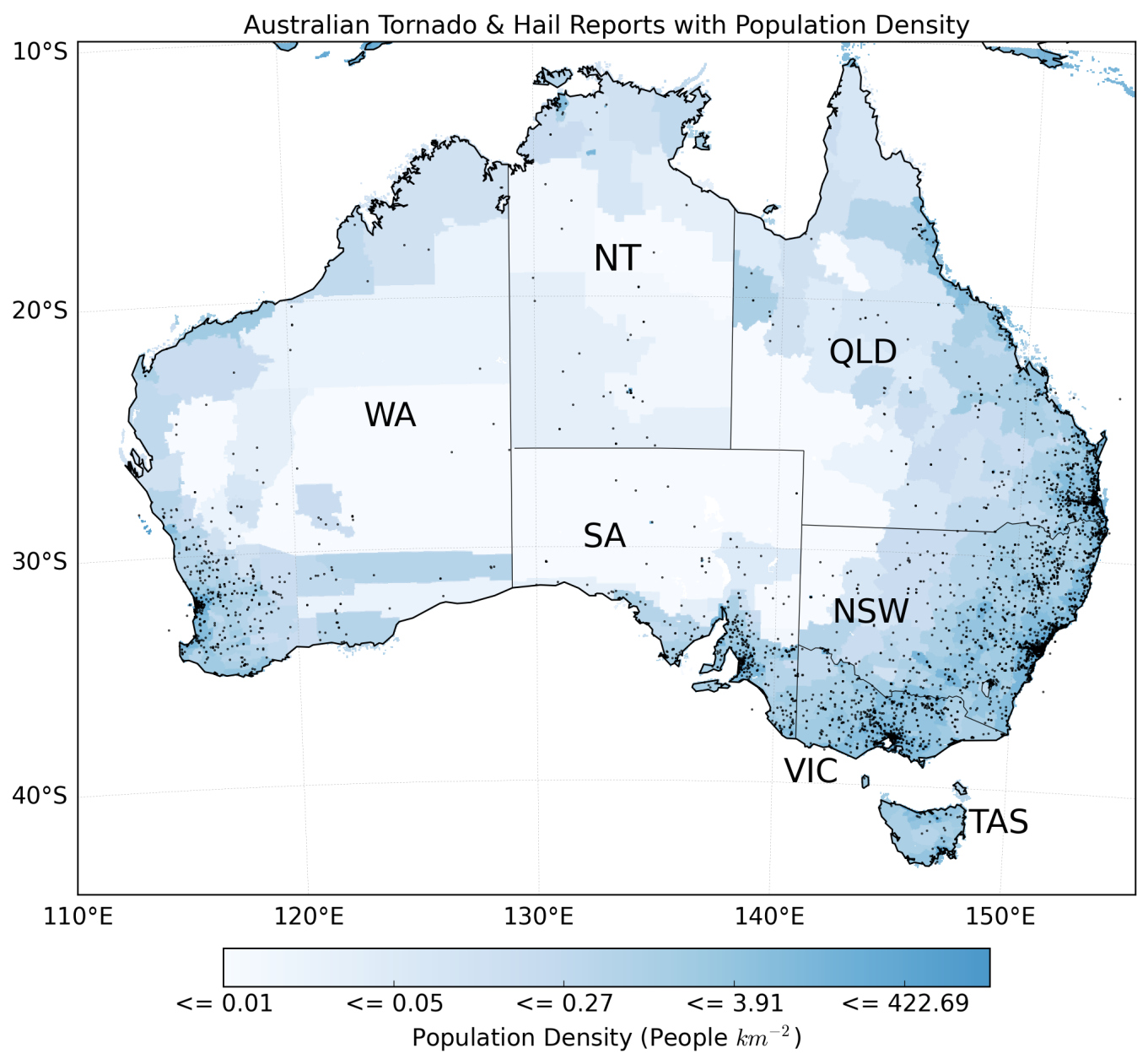

Figure 1: Hail and tornado reports from the Bureau STA for the period 1795-2014, and gridded non-adjusted population density chloropleth as of the year 2000 from the Center for International Earth Science Information Network Gridded Population of the World, Version 3, at 2.5 arc-minute resolution. States are indicated by their respective boundaries and common abbreviations, QLD: Queensland, NSW: New South Wales, VIC: Victoria, TAS: Tasmania, SA: South Australia, NT: Northern Territory, WA: Western Australia. 


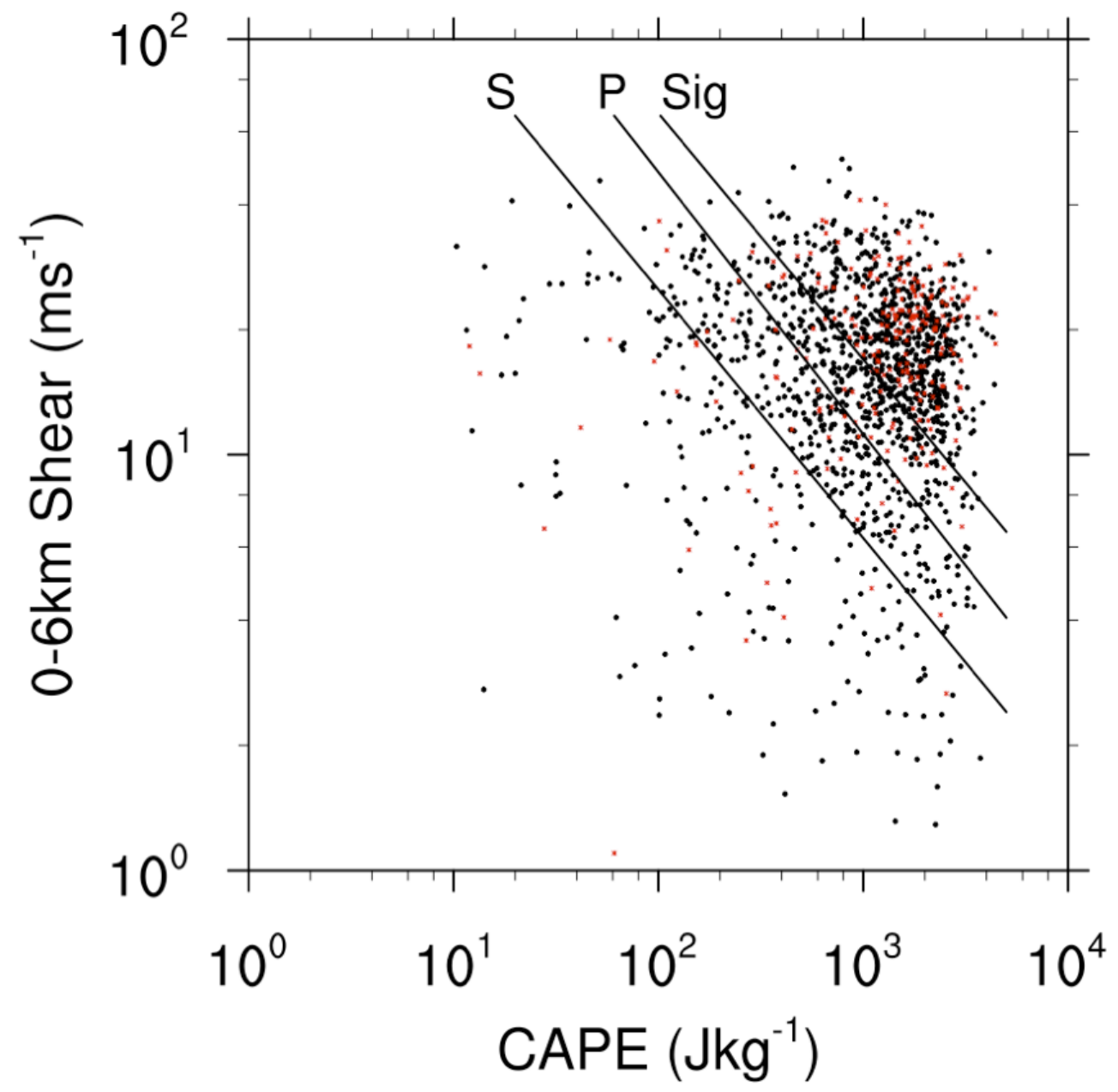

Figure 2: $\log (\mathrm{CAPE})-\log (\mathrm{S} 06)$ phase space for 1550 unique severe and significant severe Australian model-derived proximity soundings. Discriminant lines shown correspond to the discriminant determined (left to right) for severe thunderstorms from non-severe thunderstorms based on POD (Eq. 7 from Allen et al. (2011) marked S), potentially significant severe thunderstorms $(\mathrm{P})$ from severe thunderstorms which corresponds to a line drawn between the maximum and minimum variation lines (Eq. 6 from Allen et al. (2011) marked $\mathrm{P}$ ), and significant severe thunderstorms from severe thunderstorms (Eq. 4 from Allen et al. (2011) marked Sig). Used with permission from Allen et al. (2011). 


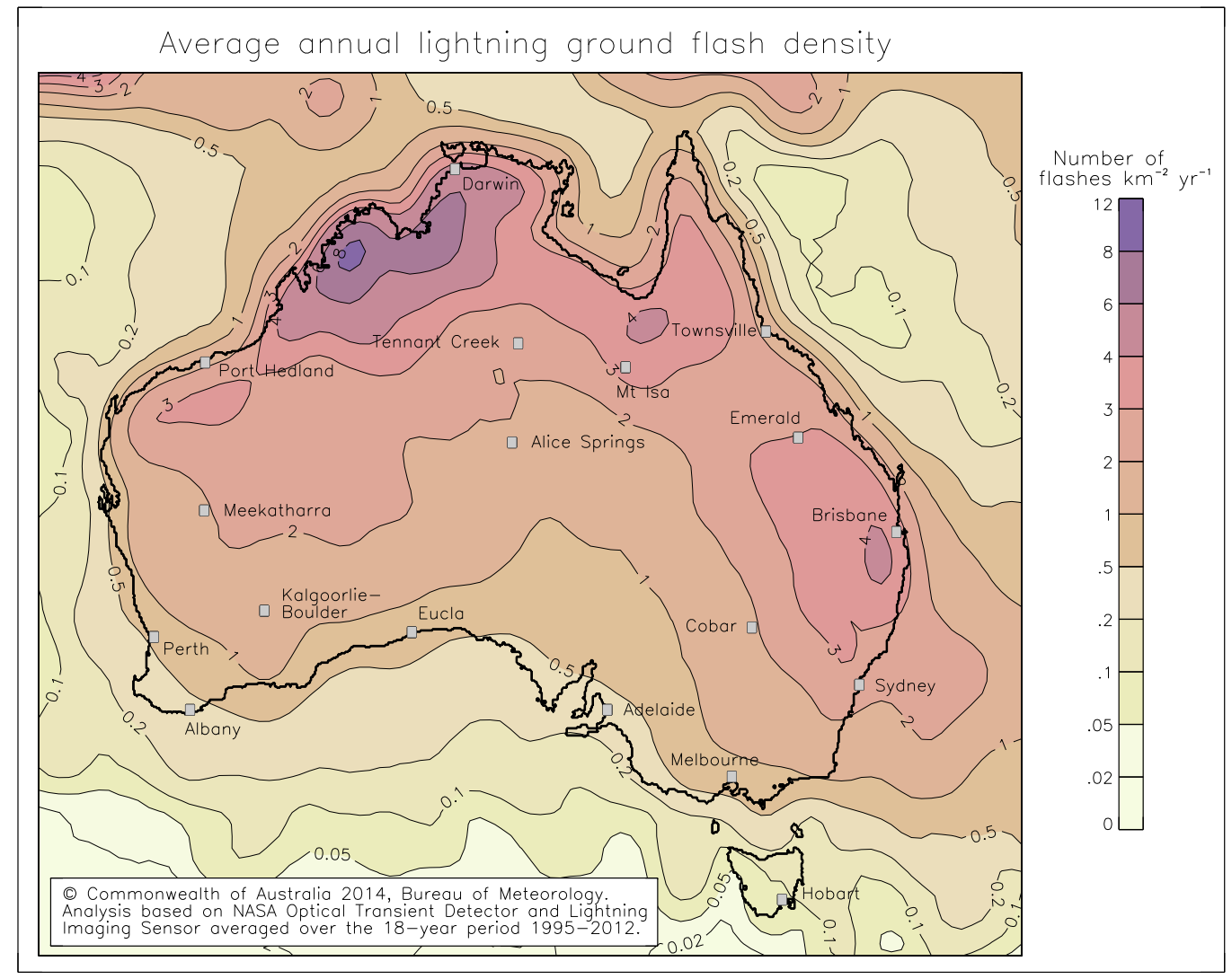

Figure 3: Remotely-sensed ground-flash lightning observation density (flashes $\mathrm{km}^{-2} \mathrm{yr}^{-1}$ ) for the period 2005-2012, with major population centers indicated. Used with permission from Dowdy and Kuleshov (2014). 


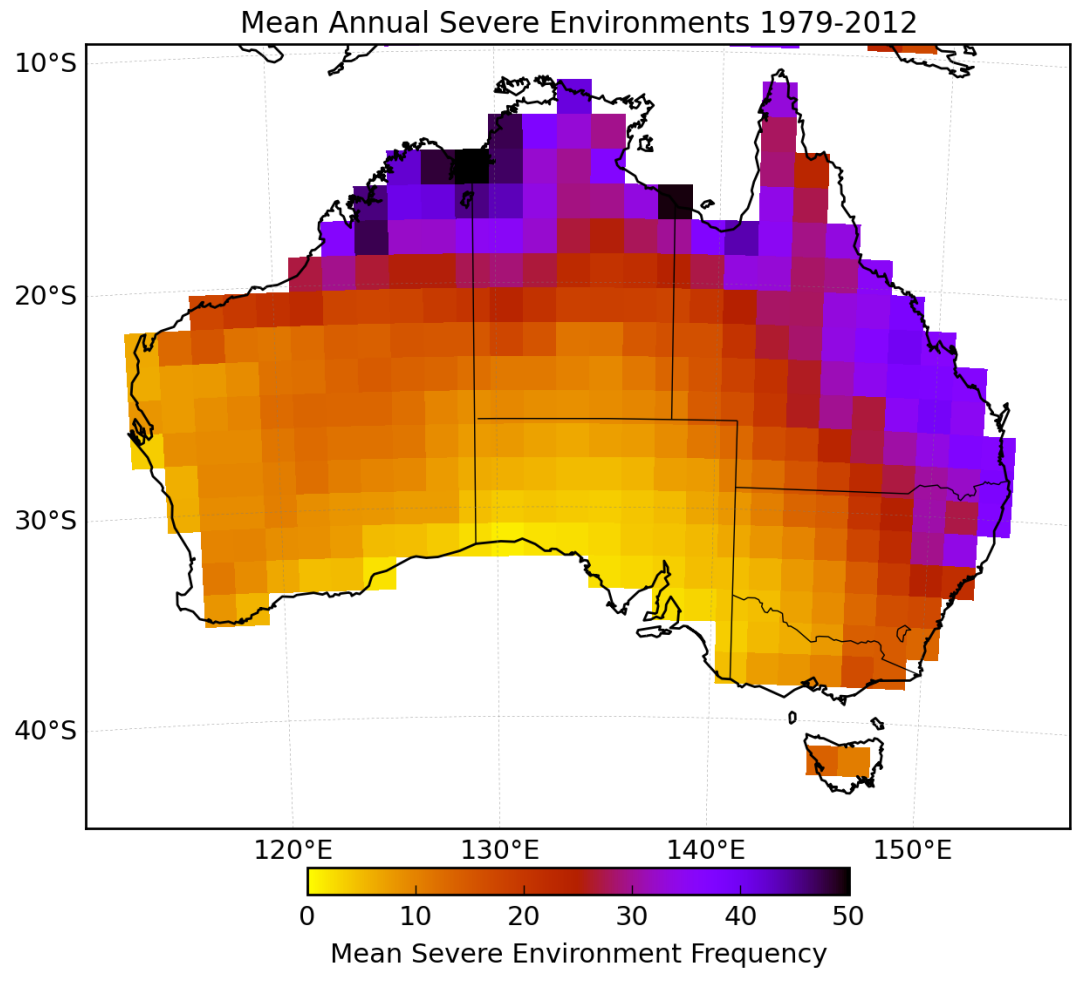

Figure 4: Annual mean distribution of favorable severe thunderstorm environments for the period September 1979 to April 2011. Frequency is the number of days where SEV environments exceed the severe discriminant of Allen et al. (2011) at each grid point of the ERA-Interim reanalysis for Australia. Favorable environments must also satisfy the conditions: MLCIN $<25 \mathrm{Jkg}^{-1}, \mathrm{~S} 06>7.5 \mathrm{~ms}^{-1}, 700$ to $500 \mathrm{hPa}$ Lapse rate $>6.5 \mathrm{Kkm}^{-1}$, and occur over land. Adapted from Figure 8a. of Allen and Karoly (2014) 

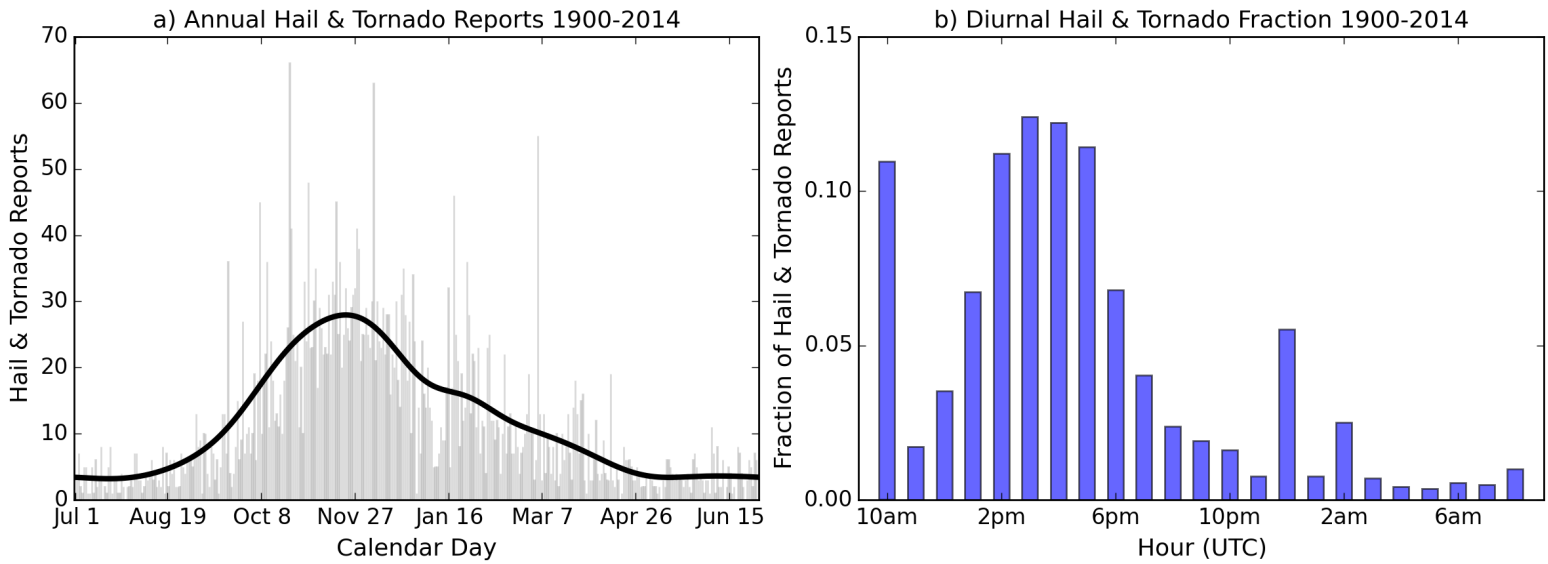

Figure 5: a) Seasonal and b) diurnal cycles of hail and tornado events for Australia based on Bureau of Meteorology STA reports for the period 1900-2014. The annual cycle is fitted with a periodic 15-day Gaussian kernel smoothing procedure to preserve the structure of the cycle at the end of year boundaries. Diurnal timing of reports is in local time, and represented at the fraction of reports over the 24 hourly blocks. 

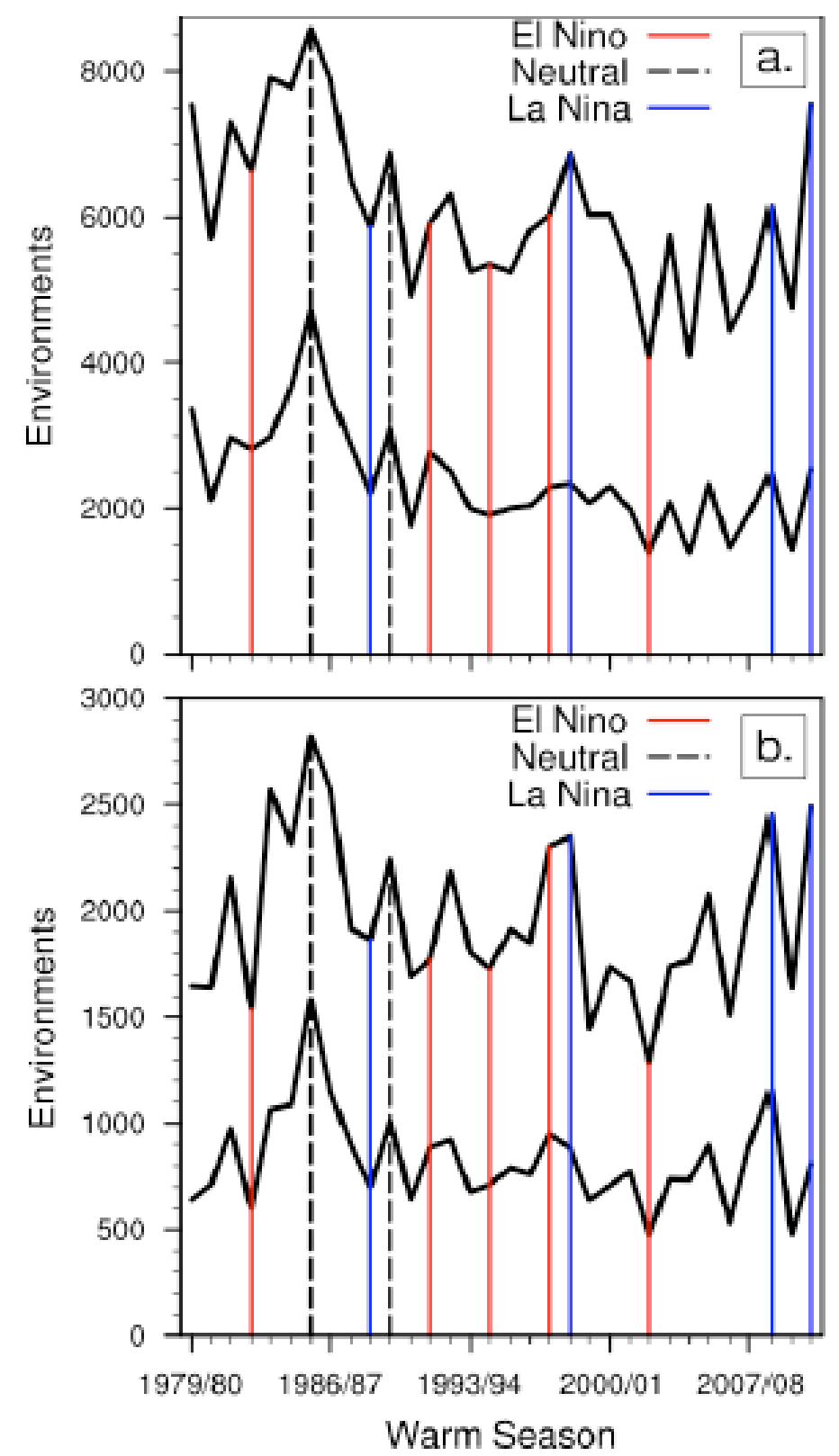

Figure 6: Time series of the total number of environment days 19792011. (a) Total number of environments in Australia exceeding the severe discriminant (top line), and number of environments exceeding the significant severe discriminant (bottom line). Significant ENSO events (El Niño, La Niña, Neutral) over the period are shown in color. (b) As for (a) except total number of environments over eastern Australia. Adapted from Figure 10 of Allen and Karoly (2014) 
a) Hail Report Density 1795-2014

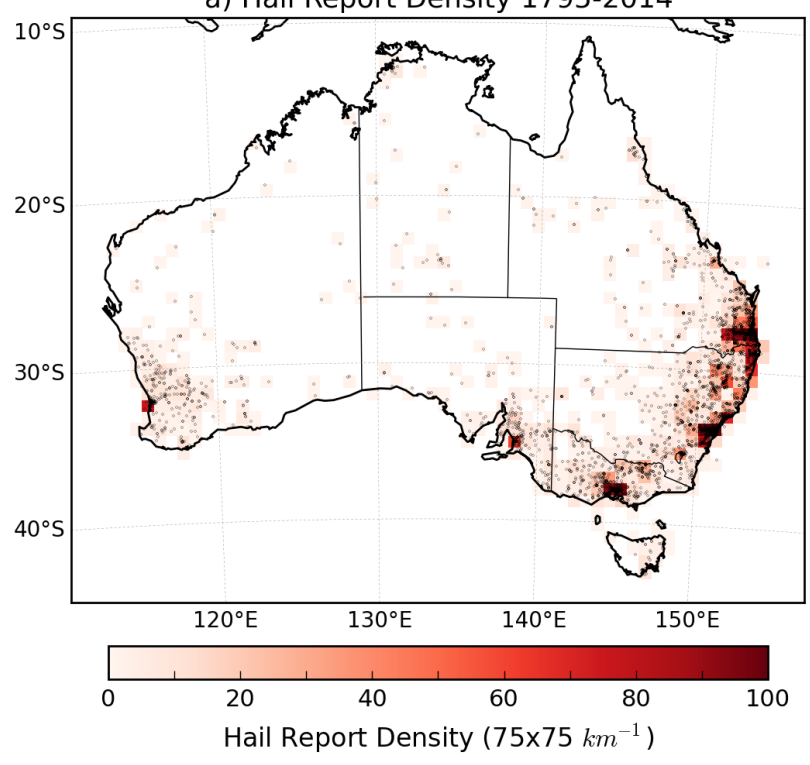

b) Hail (>5cm) Report Density 1795-2014

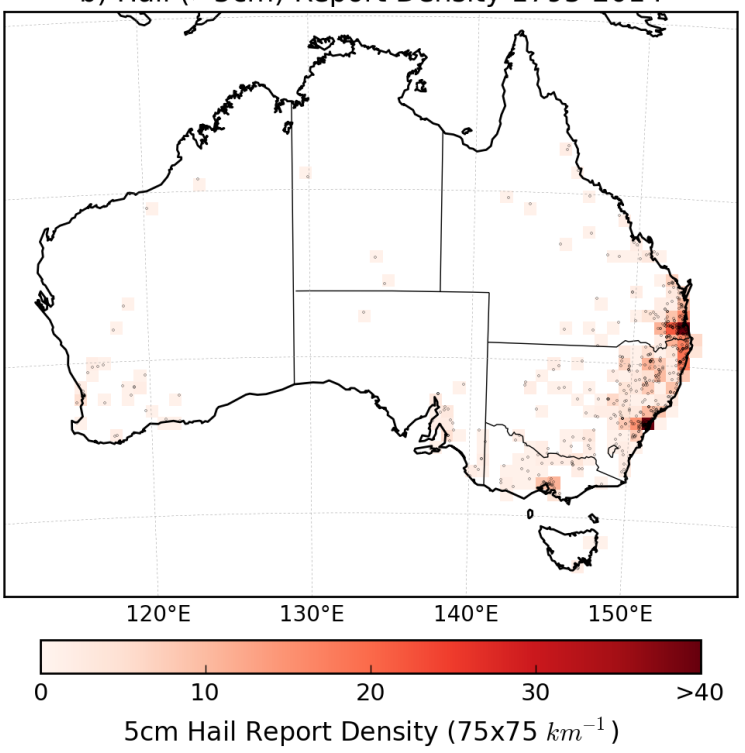

Figure 7: a) Total density of Bureau STA sourced Hail reports from 1979-2014, aggregated on a $75 \times 75 \mathrm{~km}$ grid and overlaid with point report locations, b) As for a) except $>5 \mathrm{~cm}$ hail reports. 


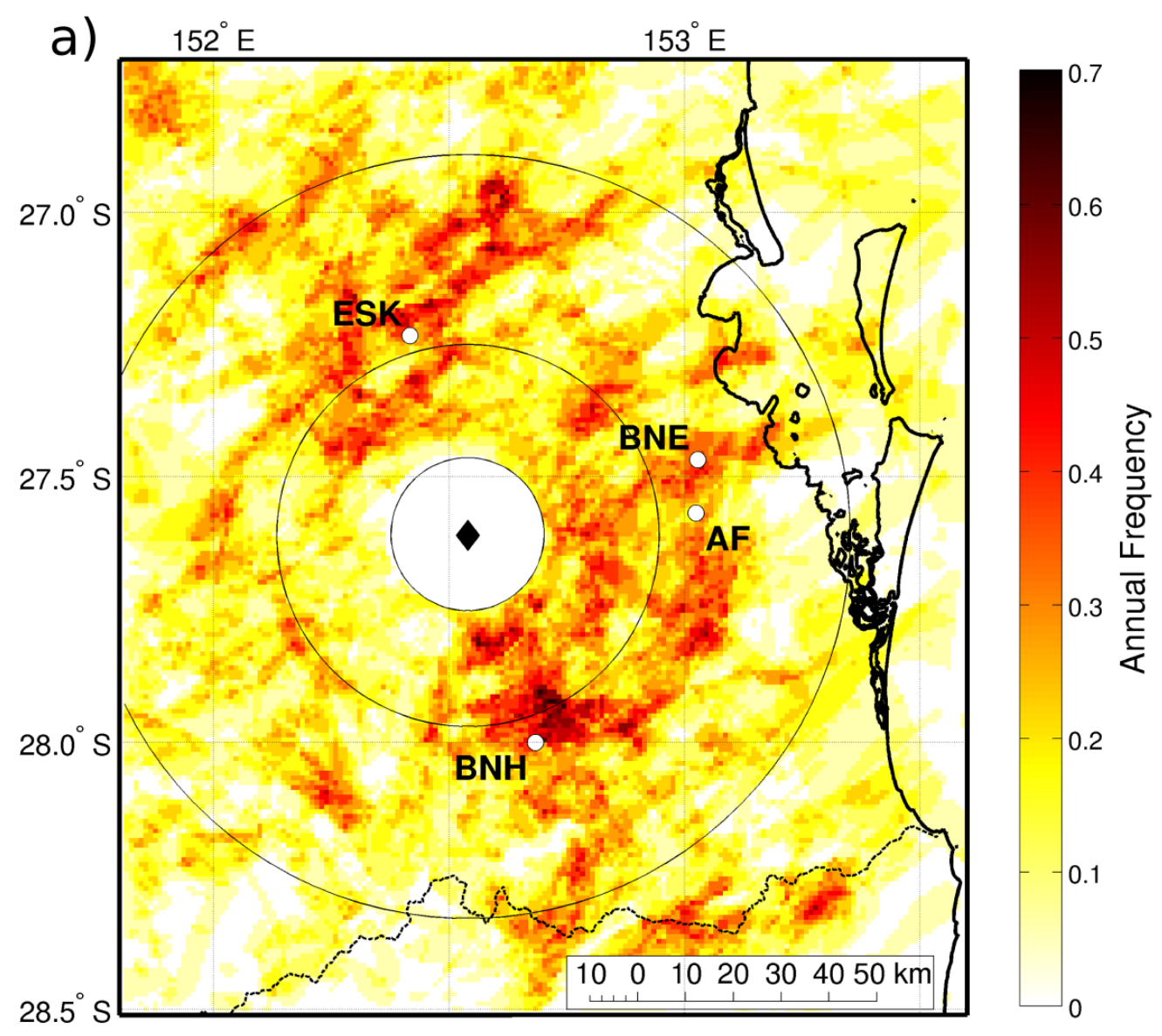

Figure 8: Cumulative mean annual incidence of radar-derived hail in excess of $21 \mathrm{~mm}$ detected using the Maximum Expected Size of Hail (MESH) algorithm. MESH is calculated on a $1 \mathrm{~km}$ grid for every $10 \mathrm{~min}$ scan using volumetric data from the Marburg radar (July 1997 to June 2015) and the nearest Brisbane airport soundings in time. Figure 2a of Soderholm et al. (2016), used with the authors permission. 


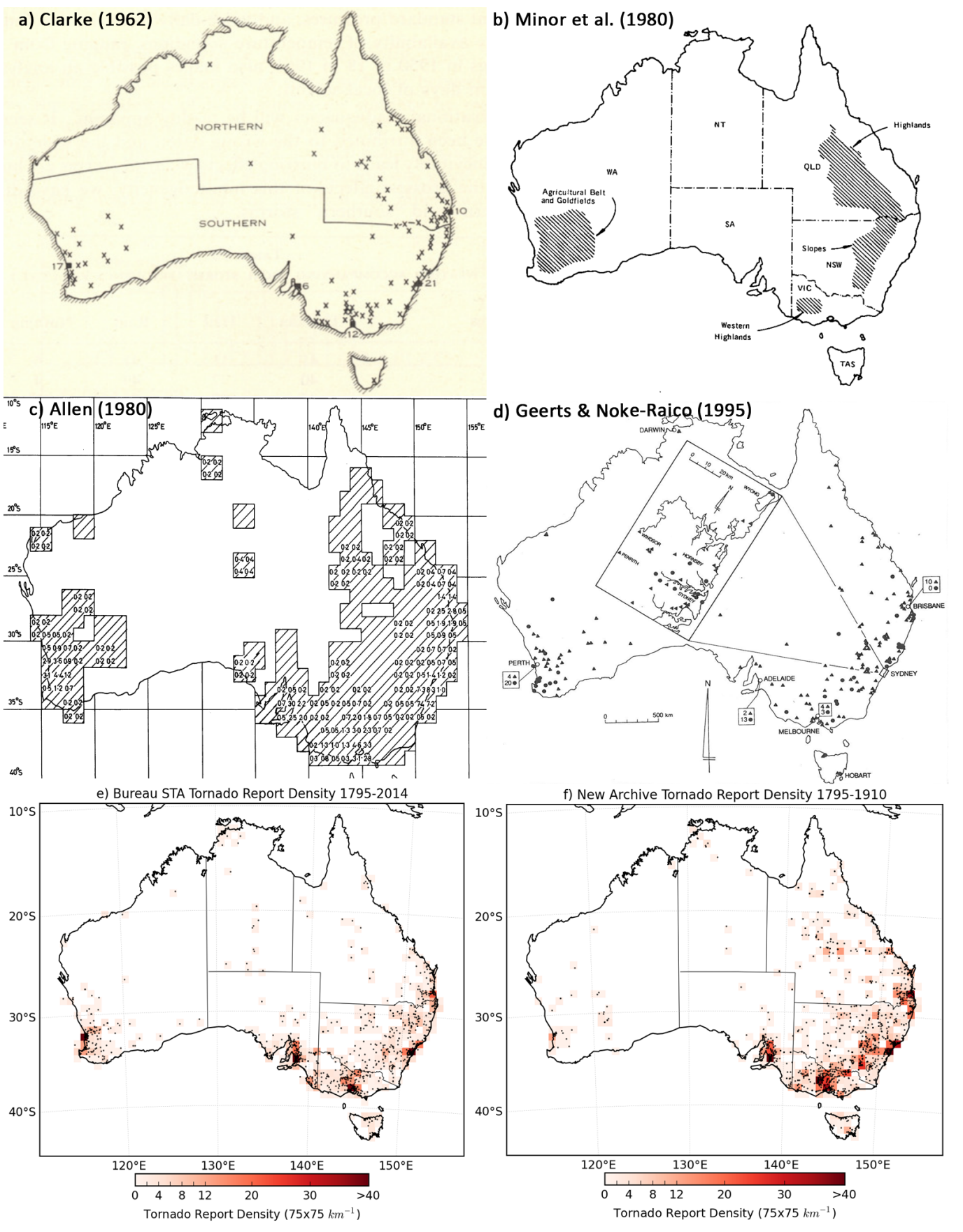

Figure 9: Evolution of the spatial climatologies of tornadoes in Australia through time. a) 167 tornadoes from 1950-1961, adapted from Clarke (1962) b) Areas with tornado frequency comparable to the active states of the U.S., adapted from Minor et al. (1980), c) Gridded 2x2 degree density of tornadoes from 1950-1959, adapted from Allen (1980), d) Distribution of the Bureau STA record 4934 tornadoes reported during 1960-1992. The triangles were used to denote summer events $(22 / 9-21 / 3)$ and the circles winter events (22/3 - 21/9). Adapted from Geerts and Noke-Raico (1995), e) Total density of Bureau STA sourced tornado reports from 1795-2014, aggregated on a $75 \times 75 \mathrm{~km}$ grid and overlaid with point report locations, and f) Reanalysis of observed Australian tornadoes from historical archives gridded analogously to e) for the period 1795-1910 (Allen and Allen, 2014). 


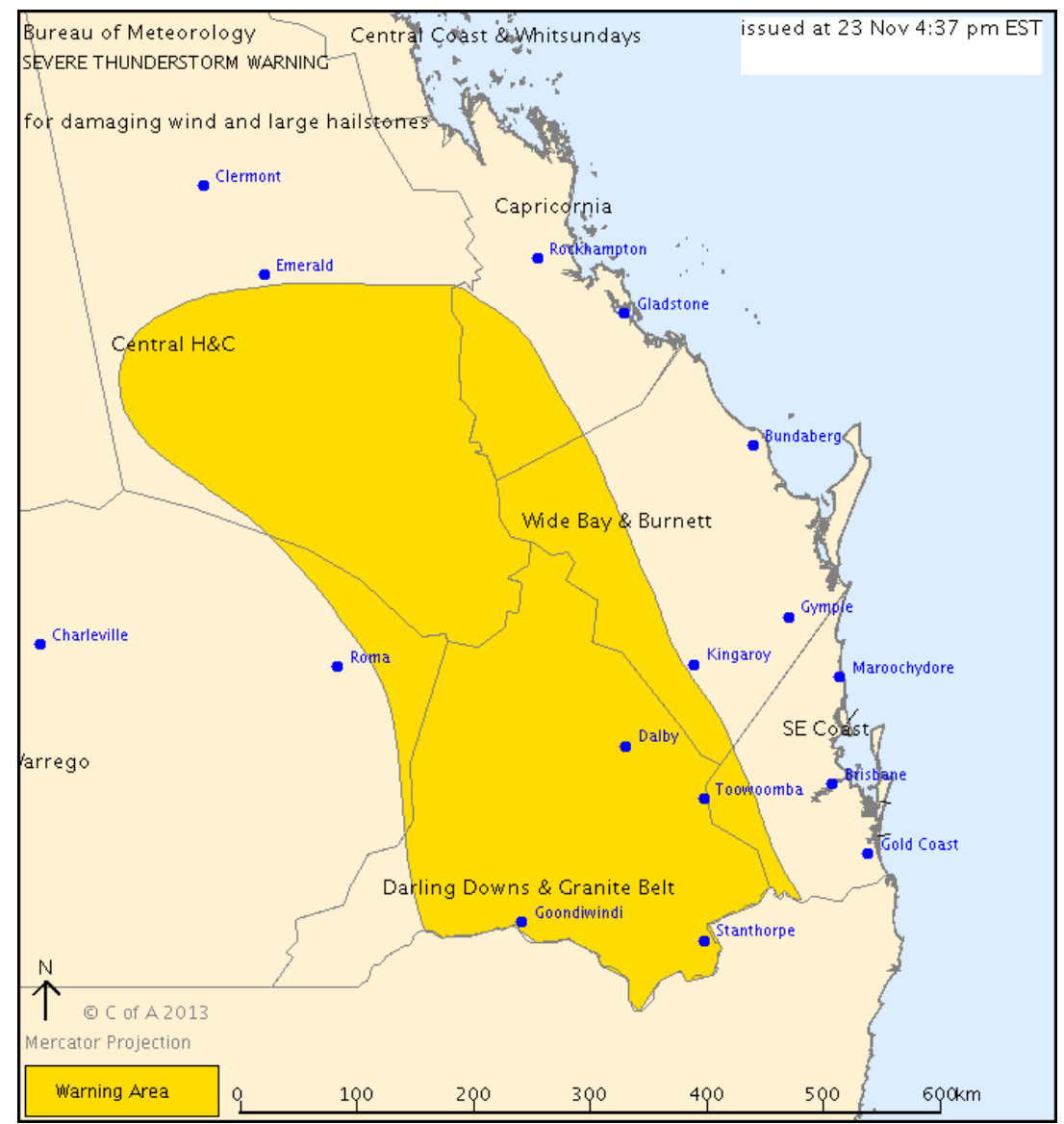

Figure 10: A typical areal state based warning from 23rd November 2013 for severe thunderstorms over the southeast part of QLD. Courtesy H. Richter, Australian Bureau of Meteorology. 


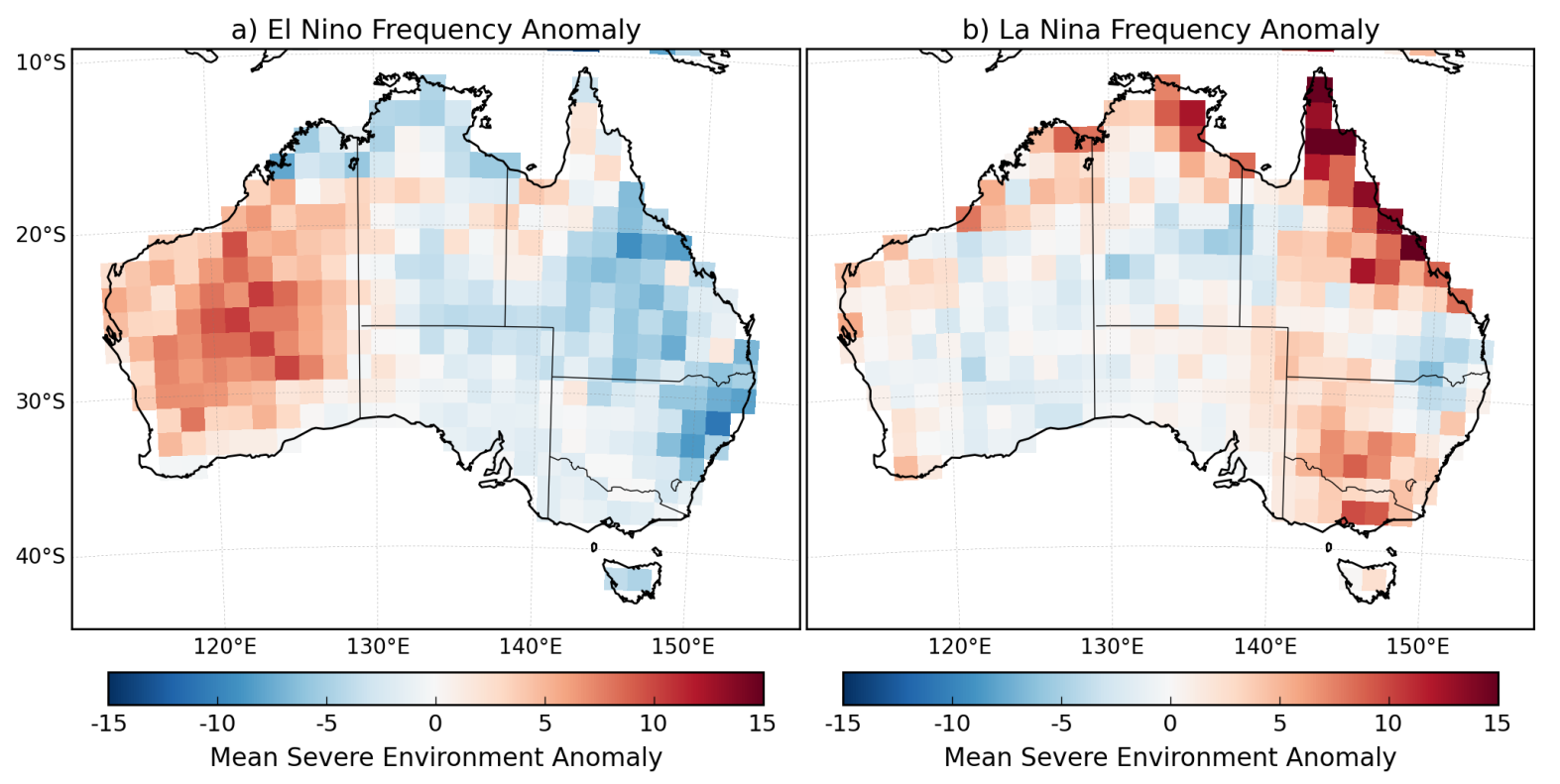

Figure 11: a) Composite anomaly number of severe thunderstorm environments for three El Niño warm seasons determined for Southern Oscillation Index $<8$ $(1982 / 1983,1991 / 1992,1994 / 1995)$. b) As for a) except for three La Niña warm seasons determined for Southern Oscillation Index >+8 (1988/1999,1998/1999,2010/2011). Adapted from Fig 11 Allen and Karoly (2014) 


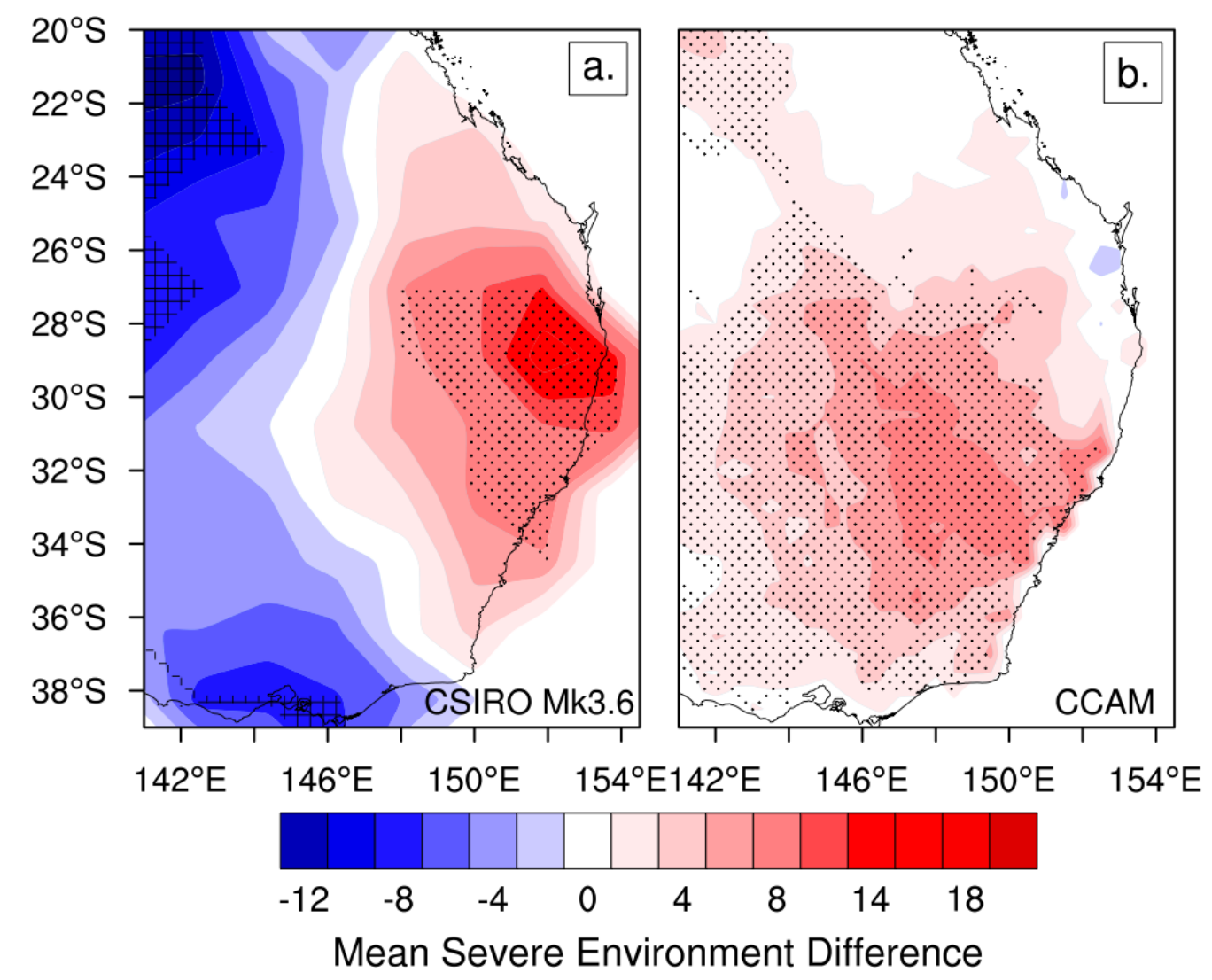

Figure 12: Mean frequency anomaly for severe thunderstorm environments between 20792099 and 1980-2000 over eastern Australia for a) CSIRO Mk3.6 and b) CCAM. Stippling illustrates significant increases to the twenty-first-century mean above the 97.5 th percentile, while hatching indicates significant decreases below the 2.5 th percentile as determined using a bootstrapping procedure. Units are changes to the number of environments per season. Used with permission (their Figure 10) from Allen et al. (2014b) 